3

\title{
Alternative-Fuel-Vehicle Policy Interactions Increase U.S. Greenhouse Gas Emissions
}

\author{
Alan Jenn \\ Assistant Professional Researcher \\ Institute of Transportation Studies \\ University of California, Davis
}

\author{
Inês L. Azevedo \\ Professor \\ Engineering and Public Policy \\ Carnegie Mellon University
}

\author{
Jeremy J. Michalek \\ Professor \\ Engineering and Public Policy \\ Mechanical Engineering \\ Carnegie Mellon University
}

\begin{abstract}
The transportation sector is currently the largest contributor of greenhouse gas (GHG) emissions in the United States, and light-duty vehicles produce the majority of transportation emissions. Federal standards for fleet-averaged vehicle GHG emission rates and their corresponding corporate average fuel economy standards cap GHG emissions of the US light-duty vehicle fleet. In addition, two key policies aim to encourage a future fleet transition to alternative fuel vehicle (AFV) technologies: (1) incentives that treat AFVs favorably in the federal GHG standard, and (2) state zero-emission vehicle (ZEV) policy, which mandates AFV sales in some states. While each of these AFV policies can encourage AFV adoption, we show that net GHG emissions increase when both policies are present simultaneously. Specifically, we estimate changes in life cycle GHG emissions and gasoline consumption, relative to a pure federal fleet GHG standard (without AFV incentives or mandates), resulting from the introduction of (1) AFV incentives in federal fleet GHG policy, (2) state ZEV mandates, and (3) the combination of the two. We find that under fairly general conditions the combined AFV policies produce higher GHG emissions than either policy alone. This result is a consequence of state mandates increasing AFV sales in the presence of federal incentives that relax the fleet GHG standard when AFVs are sold. Using AFV sales projections from the Energy Information Administration and the California Air Resources Board, we estimate that the combined policies produce an increase on the order of 100 million tons of $\mathrm{CO}_{2}$ emissions cumulatively for new passenger cars sold from 2012 through 2025 relative to a pure GHG standard. AFV incentives in the GHG standard conflate policy goals by encouraging AFV adoption at the cost of higher fleet GHG emissions, and they permit even higher fleet GHG emissions when other policies, such as the ZEV mandate, increase AFV adoption.
\end{abstract}

\section{INTRODUCTION}

Federal light-duty fleet greenhouse gas (GHG) emission standards and associated Corporate Average Fuel Economy (CAFE) standards cap average vehicle emission rates in the U.S. Additionally, to encourage a long term transition to technologies capable of operating with near-zero emissions, federal and state policies encourage automakers to sell alternative-fuel vehicles (AFVs) - vehicles that can operate on fuels other than gasoline and diesel. AFVs include (1) dual-fuel vehicles, such as flex-fuel vehicles (FFVs) and plug-in hybrid electric vehicles (PHEVs), and (2) single-fuel vehicles, such as battery electric vehicles (BEVs) and fuel cell vehicles (FCV). Two important policies intended to encourage AFV adoption are:

1. AFVIs: Incentives in federal light-duty vehicle GHG emission standards for automakers that sell AFVs count AFVs favorably in compliance calculations. We refer to these AFV incentives as AFVIs.

2. ZEV: California and nine other states mandate AFV sales under state zero emission vehicle (ZEV) policy. These states represented approximately $35 \%$ of the U.S. new vehicle market in 2017 . The ZEV policy requires large automakers that sell vehicles in the state to sell low- and zero-tailpipe-emission vehicles (primarily AFVs) as a prescribed portion of their state fleet sales.

We examine the individual and combined effect of these federal and state policies that promote AFVs on fleet GHG emissions and gasoline consumption. We first review federal automotive CAFE/GHG policy, state ZEV policy, and relevant literature; we then develop a model of fleet emissions and gasoline consumption and apply it to policy scenarios involving CAFE/GHG policy both with and without AFVI and ZEV policies under a range of 
assumptions; we identify a set of sufficient conditions under which our key findings hold; and finally, we discuss the implications of our findings.

\subsection{Federal Corporate Average Fuel Economy Standards and Greenhouse Gas Emission Standards}

CAFE standards were first implemented in the Energy Policy Conservation Act of 1975 to increase vehicle fuel efficiency and reduce reliance on foreign oil, following the 1973 oil crisis ${ }^{1}$. Since their inception, the standards have been implemented by the National Highway Traffic Safety Administration (NHTSA) in the Department of Transportation (DOT). The standards require manufacturers to meet sales-weighted average fuel efficiency targets for each model year sold, with separate standards for passenger vehicles and light-duty trucks. The initial set of standards came into effect in 1978 for passenger cars and 1979 for light-duty trucks. Over time, the stringency of the standards was increased. By 1990, the passenger car standards were set at 27.5 miles per gallon (MPG), as measured using a 2-cycle laboratory test. Seven years later, the light-duty truck standards were also increased to 20.7 MPG. In 2012, the standards were modified to a footprint-based standard, ${ }^{2}$ where automakers that sell smaller cars have higher fuel efficiency targets. In addition, due to a court ruling in $2007^{3}$ that required the Environmental Protection Agency (EPA) to regulate carbon dioxide as a pollutant, the EPA wrote a new set of fleet GHG standards that were harmonized with the NHTSA CAFE standards in order to have comparable stringency (GHG emissions are proportional to gasoline consumption $)^{4,5}$. The newest set of standards is for model years 2017 through 2025 , with NHTSA regulating fuel efficiency (MPG) and EPA regulating equivalent carbon dioxide emission rates (grams of $\mathrm{CO}_{2}$ per mile). The Trump administration has proposed a revised set of standards with reduced stringency for model years $2022-2026^{6}$.

The current set of CAFE and GHG rules each contain a provision establishing a set of incentives for automakers to sell AFVs. The CAFE AFV incentives are longstanding and set by statute, including a factor for converting alternative fuel consumption into a gasoline equivalent when assessing compliance. The incentives in the GHG rule include multipliers and weighting factors set by EPA. A multiplier allows each AFV sale to count in compliance calculations as though it were multiple sales. A weighting factor treats AFV emissions in compliance calculations as though they are lower than they actually are. Both incentives relax the GHG requirement for an automaker's fleet (Jenn, Azevedo, \& Michalek, 2016). The full list of AFV incentives are summarized in Table S1 of the Supplementary Information (SI). For dual-fuel vehicles, EPA determines the portion of vehicle miles traveled assumed to be propelled by the alternative fuel, and we adopt their estimates.

The EPA released reports in 2010 and in 2012 evaluating the 2012-2016 and 2017-2025 CAFE standards, respectively. They estimate that the fuel efficiency standards are expected to cumulatively reduce $\mathrm{CO}_{2}$ emissions by 960 million metric tons for model years 2012-2016 and 2 billion metric tons for model years 2017 through 2025 over the lifetime of the vehicles ${ }^{7,8}$.

Independent researchers have estimated emissions savings due to CAFE/GHG policy using a variety of methods and arrived at reasonably consistent estimates: Using various equilibrium frameworks, Morrow et al. (2010) estimate reductions on the order of 1.2 to 1.6 billion metric tons of $\mathrm{CO}_{2}$ for vehicles in operation from 2010 through 2030 (extending CAFE through 2030); Karplus and Paltsey (2012), using a general equilibrium approach, estimate a cumulative savings of 2.7 billion metric tons of $\mathrm{CO}_{2}$ over the lifetime of vehicles sold from 2012 through 2025; Sarica and Tyner (2012), using a hybrid MARKAL model, estimate reductions of 150-200 million metric tons of $\mathrm{CO}_{2}$ annually by 2030; and O'Rear et al. (2015), also using MARKAL, estimate savings of $10.5 \%$ in $\mathrm{CO}_{2}$ emissions resulting from CAFE in 2025 relative to stagnant standards. Bastani et al. (2012) use expert elicitation and estimate

\footnotetext{
${ }^{1}$ Energy Policy and Conservation Act, 1975. Public Law. 94163. United States Congress

${ }^{2}$ A vehicle footprint measures the area resulting from the product of the wheelbase and track length of the vehicle. The intent of the footprintbased standard is to put pressure on all vehicles to reduce fuel efficiency via technology, rather than pushing consumers into smaller vehicles.

${ }^{3}$ Massachusetts v. Environmental Protection Agency, 127 S. Ct. 1438, 549 U.S. 497, 167 L. Ed. 2d 248 (2007).

${ }^{4}$ Federal Register Vol. 75, No. 88: Light-Duty Vehicle Greenhouse Gas Emissions Standards and Corporate Average Fuel Economy Standards; Final Rule

${ }^{5}$ Federal Register Vol. 77, No. 199: 201 and Later Model Year Light-Duty Vehicle Greenhouse Gas Emissions and Corporate Average Fuel Economy Standards

${ }^{6}$ Federal Register Vol. 83, No. 165, pp 42986-43500 “The Safer Affordable Fuel-Efficient (SAFE) Vehicles Rule for Model Years 2021-2026 Passenger Cars and Light Trucks", Notice of Proposed Rulemaking, August 2018.

${ }^{7}$ US EPA Regulatory Announcement. "EPA and NHTSA Finalize Historic National Program to Reduce Greenhouse Gases and Improve Fuel Economy for Cars and Trucks". Office of Transportation and Air Quality, EPA-420-F-10-014. April 2010.

${ }^{8}$ US EPA Regulatory Announcement. "EPA and NHTSA Set Standards to Reduce Greenhouse Gases and Improve Fuel Economy for Model Years 2017-2025 Cars and Light Trucks". Office of Transportation and Air Quality, EPA-420-F-12-051. August 2012.
} 
an annual decrease of 300 million tons of $\mathrm{CO}_{2}$ (with $95 \%$ confidence intervals of $100-450$ million tons) in 2025 compared to 2008 .

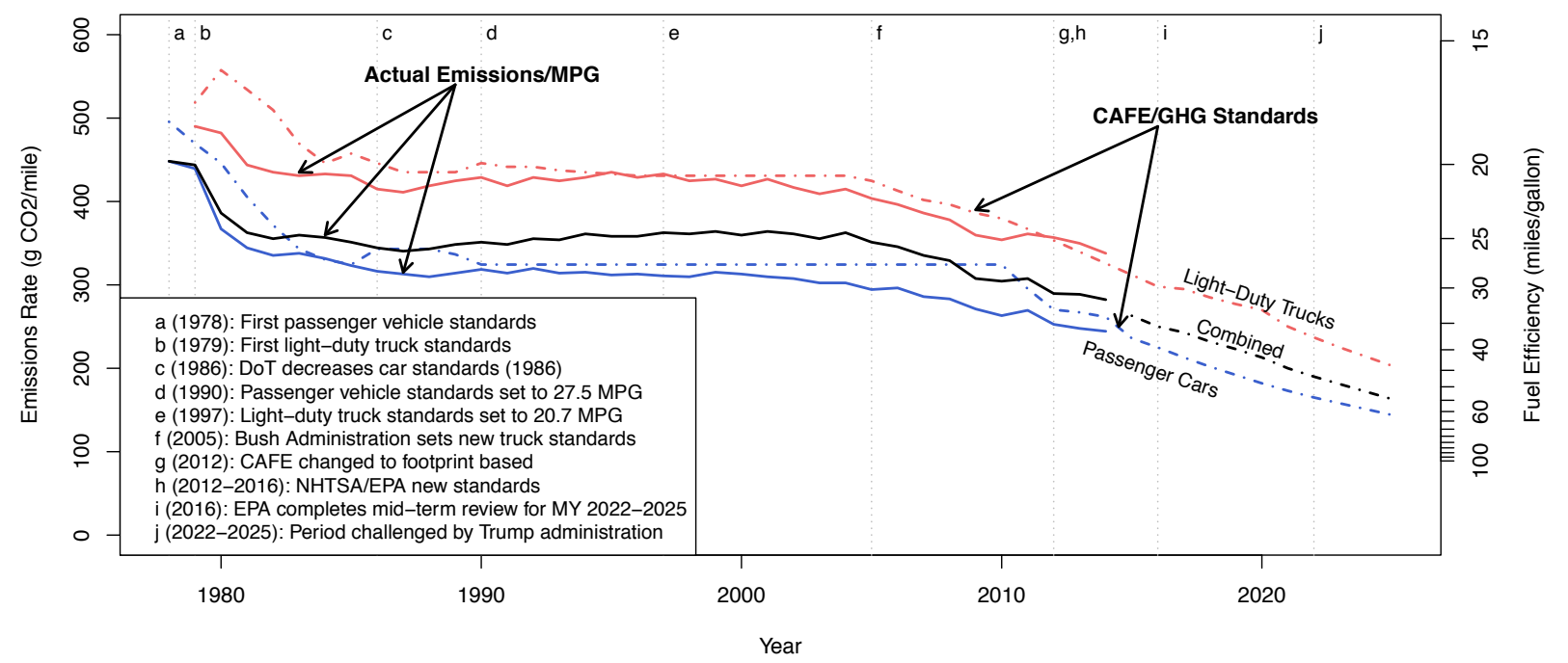

Figure 1: Historical and Expected CAFE Standards from 1978-2025 (and harmonized GHG standards from $2012-$ $2025)^{9,10,11}$. The years in parentheses correspond to the year the policy was first implemented. Each dotted line refers

to the corresponding policy standard in that year, and each solid line refers to the actual values observed in the market. Beginning in 2012 the fleet standard depends on the mix of vehicles sold (specifically size (footprint)), and the overall sales-weighted averages shown beyond 2014 are therefore based on projections of vehicle footprint sales mix.

Though the GHG standards reduce emissions, economists have repeatedly raised concerns that they do so inefficiently and have a variety of other implications. Standards that increase vehicle efficiency also reduce the marginal cost of driving and may encourage additional vehicle miles traveled, with corresponding fuel consumption, emissions, congestion, and accidents (Linn, 2016; Parry, Walls, \& Harrington, 2007), and they may result in reduced vehicle weight, affecting collision fatality rates (Jacobsen, 2013; Anderson \& Auffhammer, 2013). The standards also affect the used car market, which can incentivize consumers to keep old cars longer and can have a regressive effect (Jacobsen \& Benthem, 2015; Jacobsen, 2013; Davis \& Knittel, 2016). A key justification for fuel economy policy is that consumers may undervalue future fuel savings when purchasing a vehicle and thus benefit if fleet efficiency improves, but the evidence for this is mixed (e.g.: (Allcott \& Wozny, 2014; Busse, Knittel, \& Zettelmeyer, 2013). Economists overwhelmingly view fuel taxes and mileage taxes as more efficient policies (Parry, Walls, \& Harrington, 2007); however, the presence of other policies can change the relative advantages of alternative policy instruments (Goulder, Parry, Williams, \& Burtraw, 1999), and when regulations have incomplete scope or jurisdiction, enabling leakage of emissions from the regulated domain to the unregulated domain, it is possible for intensity standards to be more efficient than an emissions tax (Holland, 2012).

One important type of leakage can occur when state policies interact with federal policy. The federal fleet standard must be satisfied overall regardless of what vehicles are sold in a particular state, so sale of efficient or alternative fuel vehicles in one state may have no net impact on fleet emissions when the CAFE/GHG standard acts as a binding constraint. Goulder and Stavins (2011) and Goulder et al. (2012) note that California efforts to increase fleet fuel efficiency within the state lead to "leakage" where emissions gains in California are offset when higheremitting vehicles sold in the rest of the U.S. take up the slack in the CAFE/GHG standard. A Congressional Budget Office report also notes this in the context of electric vehicles, stating that under a CAFE regime, electric vehicle

\footnotetext{
${ }^{9}$ Office of Transportation and Air Quality. EPA and NHTSA Finalize Historic National Program to Reduce Greenhouse Gases and Improve Fuel Economy for Cars and Trucks. EPA-420-F-10-014. April 2010.

${ }^{10}$ Office of Transportation and Air Quality. EPA and NHTSA Set Standards to Reduce Greenhouse Gases and Improve Fuel Economy for Model Years 2017-2025 Cars and Light Trucks. EPA-420-F-12-051. August 2012.

${ }^{11}$ Hicks, Maurice. U.S. Department of Transportation. Summary of Fuel Economy Performance. December 15, 2014
} 
sales produce no near-term change in the fleet emission rate (Gecan, 2012) (though they may have long term impact if innovation or adoption of these vehicles leads to most stringent future standards). In addition to the leakage effect, Jenn et al. (2016) argue that because AFV incentives in CAFE/GHG policy loosen the standards whenever AFVs are sold, the net near-term result of increasing AFV adoption in place of conventional vehicles is an increase in fleet emissions and fuel consumption. The EPA identifies this effect in their final rule and states that "To facilitate market penetration of the most advanced vehicle technologies as rapidly as possible, EPA is proposing an incentive multiplier for compliance purposes for all electric vehicles (EVs), plug-in hybrid electric vehicles (PHEVs), and fuel cell vehicles (FCVs)"; "advanced technology vehicle multipliers ... are expected to have an impact on the fleet-wide emissions levels that manufacturers will actually achieve"; and "EPA believes it is worthwhile to forego modest additional emissions reductions in the near term in order to lay the foundation for the potential for much larger 'game-changing' GHG emissions and oil reductions in the longer term."12. We estimate the near-term increase in GHG emissions in the context of ZEV policy and compare the effect of the policies independently and jointly.

\subsection{State Zero Emission Vehicle Programs}

The ZEV requirements were originally established in 1990 as part of California's Low-Emission Vehicle regulation by CARB. The ZEV program is intended to induce a change in the technology composition of the vehicle fleet by creating a market for AFV technologies. The program works by requiring that a minimum portion of the fleet sold by each of the larger automakers in the state each year are ZEVs. It is now viewed as an important part of the strategy to help achieve California's goal (established in California Assembly Bill (AB) $32^{13}$ and AB $1493^{14}$ ) to reduce the state's GHG emissions to 1990 levels by 2020 in the face of increasing vehicle usage by establishing a market for vehicle technologies capable of producing near-zero operation-related emissions (given an appropriate fuel source and production pathway). This requirement was followed by an ambitious goal to reduce emissions to $80 \%$ of 1990 levels by $2050^{13}$. Tables S2 and S3 in the SI summarizes requirements for ZEV sales as a percentage of total sales in California. The 1990 and 1996 plans were both changed before their implementation in 1998 and 2003 , respectively. The 2001 plan faced litigation ${ }^{15}$ in state lawsuits for linking ZEV credits to fuel efficiency metrics, during which an injunction was issued that prevented CARB from enforcing ZEV mandates in 2003 and 2004.

CARB amended the ZEV requirements in 2003, requiring manufacturers to sell 2\% pure ZEVs (BEVs or FCVs), 2\% advanced technology partial-ZEVs (AT-PZEVs, which include PHEVs and hybrid electric vehicles (HEVs)), and 6\% partial ZEVs (PZEVs, which are fuel efficient conventional vehicles) starting in 2005. However, manufacturers were given an alternative path of compliance, allowing AT-PZEVs to meet the ZEV requirements as long as the manufacturer sold 250 hydrogen FCVs through 2008 and 2,500 FCVs in 2009 through 2011. In addition, only manufacturers selling more than 60,000 vehicles annually in the state of California are required to meet the full ZEV compliance mandate (the five manufacturers are Ford, GM, Honda, Nissan, and Toyota ${ }^{16}$ ). The alternative compliance path has allowed manufacturers to meet the ZEV requirements without a drastic change in their sales. The current iteration of ZEV policy is the 2012 plan $^{17}$, which has since undergone a midterm review in $2017^{18}$ requiring sales of four vehicle categories: ZEVs (FCVs and BEVs), transitional partial-ZEVs (TZEVs: PHEVs and dual-fuel FCVs), AT-PZEVs (HEVs, compressed natural gas vehicles (CNGVs), and methanol FCVs), and PZEVs (extremely clean conventional vehicles).

Because California's air quality standards preceded the federal Clean Air Act of 1970, California retained authority to regulate its own emissions, and other states are permitted to adopt its standards under Section 177 of the Clean Air Act (this authority is being challenged by the Trump administration). ${ }^{6}$ Several other states that adopted California's ambient air quality standards also elected to regulate sales of their vehicles under the ZEV policy. These states are Connecticut, Maryland, Massachusetts, New York, Rhode Island, Vermont, Oregon, Maine, and New Jersey $^{19}$.

\footnotetext{
${ }^{12}$ p. 74869 and 74878, Federal Register Vol. 77, No. 199: 201 and Later Model Year Light-Duty Vehicle Greenhouse Gas Emissions and Corporate Average Fuel Economy Standards

${ }_{13}^{13}$ Assem. Bill 32, 2005-2006 Reg. Sess. (Cal. 2006) www.leginfo.ca.gov/pub/05-06/bill/asm/ab_0001-0050/ab_32_bill_20060927_chaptered.pdf

${ }^{14}$ Assem. Bill 1493, 2002-2003 Reg. Sess. (Cal. 2002). www.arb.ca.gov/cc/ccms/documents/ab1493.pdf

${ }^{15}$ Central Valley Chrysler-Plymouth, Inc., et al. v. Witherspoon, Case No. CIV F-02-05017 REC SMS (E.D. Cal.); Liberty Motors, Inc., et al. v. California Air Resources Board, et al., Case No. 02 CE CG 00039 (Superior Court for Fresno County); Daimler Chrysler Corp. et al. v. California Air Resources Board et al., Case No. 02 CE CG 04456 HAC (Superior Court for Fresno County).

${ }^{16}$ California Environmental Protection Agency, Air Resources Board: Fact Sheet. http://www.arb.ca.gov/msprog/factsheets/2003zevchanges.pdf

${ }^{17}$ California Air Resources Board. Zero-Emission Vehicle Standards for 2009 through 2017 Model Year Passenger Cars, Light-Duty Trucks, and Medium-Duty Vehicles, S. 1962.1: https://www.arb.ca.gov/msprog/zevprog/zevregs/1962.1_Clean.pdf

${ }^{18}$ California Air Resources Board. California's Advanced Clean Cars Midterm Review:

$\mathrm{https}: / /$ www.arb.ca.gov/msprog/acc/mtr/acc_mtr_finalreport_full.pdf

${ }^{19}$ ZEV Program, Center for Climate and Energy Solutions. http://www.c2es.org/us-states-regions/policy-maps/zev-program
} 
The Zero Emission Vehicle mandate in California has been in place for over two decades under several different plans. Brown et al. (1995) provide an early perspective overview on the regulation and the role of command-and-control policies. Many of the issues described, such as emissions reductions, free market efficiency, and public support, remain issues of active discussion for AFVs today. Collantes and Sperling (2008) provide a review of ZEV policy origins and history, drawing on discussion with policy founders and stakeholders and identifying motivations for how and why various aspects of ZEV policy were constructed. Sperling and Eggert (2014) argue that ZEV accomplishes a necessary role in the transportation sector to meet California's aggressive energy and climate targets for 2030 and beyond, in part because market mechanisms, such as carbon taxes or capand-trade programs, face huge political resistance and fail to address a number of market failures. While automakers resisted ZEV policy, Wesseling et al. $(2014 ; 2015)$ observe an industry transition from defensive toward acceptance and eventual proactive support for the socio-technical change. ZEV policy has been estimated to result in a reduction of 470,000 tons of $\mathrm{CO}_{2}$ reduced in the Bay Area, due to EV deployment, by 2020 (Witt, Bomberg, Lipman, \& Williams, 2012) and 50 million tons of $\mathrm{CO}_{2}$ avoided total by 2025 (Cunningham, 2010). We show that despite potential local changes, in the presence of a binding fleet GHG standard with AFV incentives, ZEV policy results in increased net U.S. emissions.

\subsection{Other Alternative Fuel Vehicle Policies}

There are a number of other policies, both incentives and regulations, that help promote the adoption of AFVs. For example, both Renewable Fuel Standards and Low Carbon Fuel Standards aim to lower the total carbon intensity of transportation fuels by promoting alternative energy and fuels such as ethanol, compressed natural gas, and electricity. Additionally, there are various federal, state, and local incentives for AFVs, including monetary (e.g., tax credits or rebates such as the Plug-In Electric Drive Vehicle Credit) and non-monetary incentives (e.g., access to carpool lanes). Because incentives in CAFE/GHG policy allow automakers that sell alternative fuel vehicles to meet less stringent fleet standards, policies that increase AFV sales can interact with federal CAFE/GHG policy to produce increased U.S. emissions (Jenn, Azevedo, \& Michalek, 2016). We focus here on the interaction of federal GHG policy with state ZEV policy.

\section{MODEL}

To examine the interaction of state ZEV policy with federal AFV incentives in the GHG standard, we compare life cycle fleet GHG emissions (tons of $\mathrm{CO}_{2}$-equivalent) and gasoline consumption (gallons of gasoline) under four policy scenarios, summarized in Figure 2.

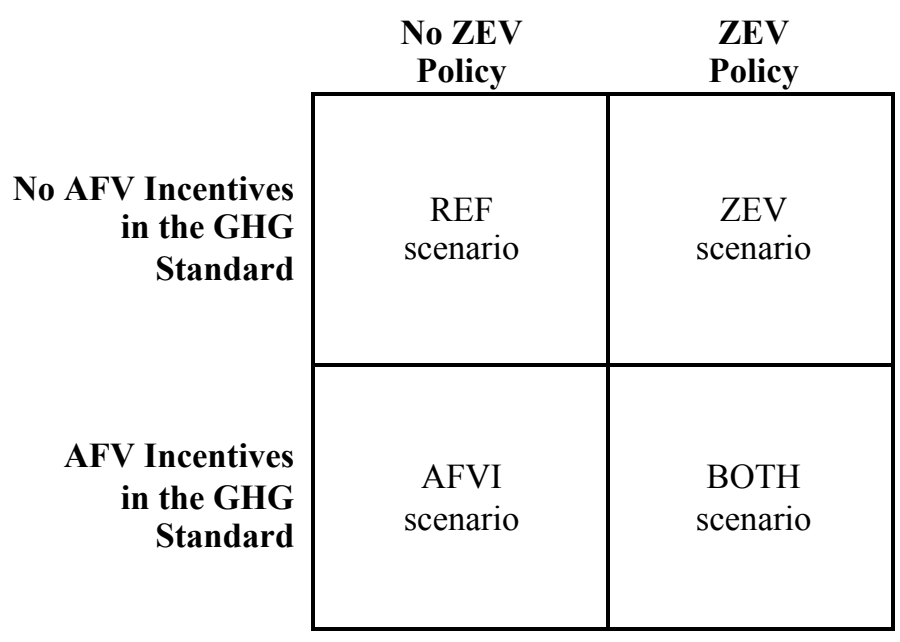

Figure 2: Illustration of policy scenarios

We first derive expressions for fleet GHG emissions and gasoline consumption by building on the framework of Jenn et al (2016) and extending it to capture life cycle emissions in real-world driving conditions when agency 
emissions estimates may differ from real world emissions. We then apply these expressions to the four scenarios of Figure 2, compute differences, and analyze results in two ways: (1) we conduct simulations using a range of assumptions for the input parameters and (2) we identify a general set of conditions under which emissions are higher in the "BOTH" scenario than in the other scenarios. Automakers must comply with both the light-duty GHG standard, enforced by the EPA, and the CAFE standard, enforced by NHTSA. The two standards are harmonized to be similar, but they have some differences due, in part, to differences in regulatory authority. We treat the light-duty fleet GHG standard as the binding federal standard because the penalty for violating the nearly-equivalent CAFE standard is relatively mild, whereas the penalty for violating the GHG standard is potentially severe (revocation of the license to sell vehicles) (Jenn, Azevedo, \& Michalek, 2016). We assume automakers overall design and price their fleets in order to exactly satisfy the federal fleet GHG constraint each year in all scenarios. We ignore the potential for automakers to bank GHG credits, as permitted in federal policy, so we expect our estimates to be optimistic, since a strategic firm might bank GHG credits in years where AFV incentives are large and then spend those credits in future years when incentives decline. Such behavior would result in larger GHG increases than we model here.

We investigate the emissions implications of the ZEV, AFVI, and BOTH scenarios relative to the REF scenario due to projected changes in the sales of AFVs as well as their associated effects on the conventional fleet. In each scenario, we aim to model real-world emissions, taking into account (1) the difference between the 2-cycle laboratory tests used for CAFE/GHG compliance calculations and the 5-cycle laboratory tests that better approximate on-road conditions, (2) upstream emissions from electric vehicle charging and potential for agency error in estimating those emissions, and (3) life-cycle emissions from vehicle production.

\subsection{Fleet GHG emissions}

We model life cycle emissions (including use-phase emissions and vehicle production emissions) from the U.S. light-duty vehicle fleet as

$$
E=v\left(\sum_{j \in J_{\mathrm{C}}} n_{j} r_{j}^{\mathrm{G}}+\sum_{j \in J_{\mathrm{A}}} n_{j}\left(p_{j} r_{j}^{\mathrm{A}}+\left(1-p_{j}\right) r_{j}^{\mathrm{G}}\right)\right)+\sum_{j \in J} n_{j} \gamma_{j}
$$

where total life cycle GHG emissions $E$ are composed of emissions associated with gasoline vehicle operations, alternative fuel vehicle operations, and vehicle production, respectively. Specifically, $J_{C}$ is the set of conventional vehicle designs, $J_{\mathrm{A}}$ is the set of AFV designs (including dual fuel vehicles), $J=J_{\mathrm{C}} \cup J_{\mathrm{A}}$ is the set of all vehicle designs, $v$ is the lifetime distance traveled per vehicle (assumed equal for all vehicles) ${ }^{20}, n_{j}$ is the number of units of vehicle $j$ sold, $r_{j}^{\mathrm{G}}$ is the GHG emissions rate of vehicle $j$ when operating on gasoline/diesel (including upstream emissions for fuel production and distribution), $r_{j}^{\mathrm{A}}$ is the GHG emissions rate of vehicle $j$ when operating on its alternative fuel (including upstream emissions for fuel production and distribution), $p_{j}$ is the portion of vehicle miles traveled for which vehicle $j$ is propelled by the alternative fuel ( $p_{j}=0$ for pure AFVs, $p_{j}=1$ for conventional gasoline vehicles, and $0<p_{j}<1$ for dual fuel vehicles), and $\gamma_{j}$ is the total GHG emissions associated with manufacturing one unit of vehicle $j$.

\subsubsection{Accounting emissions}

For each manufacturer, the EPA sets an emission standard $\bar{s}$ based on the size (footprint) of the manufacturer's vehicles and requires the manufacturer's modified sales-weighted fleet emission rate to be at or below the standard:

$$
\frac{\sum_{j \in J_{\mathrm{C}}} n_{j} \tilde{r}_{j}^{\mathrm{G}}+\sum_{j \in J_{\mathrm{A}}}\left(n_{j} m_{j}\left(p_{j} \tilde{r}_{j}^{\mathrm{A}} w_{j}+\left(1-p_{j}\right) \tilde{r}_{j}^{\mathrm{G}}\right)\right)}{N+\sum_{j \in J_{\mathrm{A}}} n_{j}\left(m_{j}-1\right)} \leq \bar{s}
$$

where the emissions rate of each gasoline and alternative fuel vehicle is weighted by its respective sales, added together, and divided by total sales, after making modifications for AFV incentives. Specifically, the AFV incentives artificially reduce the emissions of AFVs when operating on an alternative fuel by the weighting factor $w$ and

\footnotetext{
${ }^{20}$ Any significant systematic differences in VMT among vehicle types could further modify results.
} 
artificially increase the number of AFVs sold by the multiplier $m$. Here $w$ is the AFV incentive weighting factor, $m$ is the AFV incentive multiplier, $N=\sum_{j \in J_{\mathrm{C}}} n_{j}+\sum_{j \in J_{\mathrm{A}}} n_{j}$ is the total number of vehicles sold, and the tilde symbol $(\sim)$ denotes emissions as measured by the 2 -cycle laboratory regulation compliance procedure (which differs from on-road emission rates). When $w=m=1, \mathrm{Eq}$ (2) corresponds to the pure GHG standard (top row of Figure 2). Table S1 in the SI summarizes the schedule of AFV incentives in the existing standard. The AFV incentives allow automakers to effectively meet a less stringent standard than they would have been able to otherwise (Jenn, Azevedo, \& Michalek, 2016), and we provide an additional discussion in the SI. Compliance credits can be traded among automakers so that some automakers can over-comply with Eq (2) and earn credits while other automakers under-comply with Eq (2) and must buy credits from others. When the industry as a whole complies exactly with the regulation the inequality in $\mathrm{Eq}(2)$ becomes an equality.

\subsubsection{On-road emissions}

If the true on-road emission rate of each vehicle is $\delta$ times as large as measured by the regulation's 2-cycle laboratory test, and if the AFVs have an additional factor $c$ to account for the potential difference between the realworld emission rate for upstream emissions of the alternative fuel (e.g.: electricity production emissions) relative to the emission rate used in policy compliance calculations, ${ }^{21}$ then:

$$
\begin{gathered}
r_{j}^{\mathrm{G}}=\delta \tilde{r}_{j}^{\mathrm{G}} \\
r_{j}^{\mathrm{A}}=\delta\left(\tilde{r}_{j}^{\mathrm{A}}+c_{j}\right)
\end{gathered}
$$

If we solve Eq (2) as an equality for $\sum_{j \in J_{\mathrm{C}}} n_{i} \tilde{r}_{j}^{\mathrm{G}}$ and substitute it together with equations (3) and (4) into Eq (1), we obtain:

$$
E=\delta v\left(\bar{s} \sum_{j \in J} n_{j}+\sum_{j \in J_{\mathrm{A}}} n_{j} p_{j} c_{j}+\sum_{j \in J_{\mathrm{A}}} n_{j}\left(p_{j} \tilde{r}_{j}^{\mathrm{A}}\left(1-m_{j} w_{j}\right)+\left(m_{j}-1\right)\left(\bar{s}-\left(1-p_{j}\right) \tilde{r}_{j}^{\mathrm{G}}\right)\right)\right)+\sum_{j \in J} n_{j} \gamma_{j}
$$

Here the first term inside the parentheses represents the fleet emissions implied by the value of the standard itself; the second term represents additional upstream emissions for AFVs correcting for agency measurement error; the third term represents the increase in permitted fleet emissions due to AFV incentives (if $m=w=1$, this term is zero); and the last term represents emissions from vehicle manufacturing. The emissions rate $\tilde{r}_{j}^{\mathrm{G}}$ for gasoline vehicles $J_{G}$ does not appear because it is determined implicitly, together with sales volumes, to satisfy the binding fleet GHG standard in Eq (2) as an equality. Thus, our analysis is agnostic about the degree to which the slack in the fleet GHG standards is absorbed by (1) redesign of the vehicles and (2) shift of sales mix (e.g.: through re-pricing or promotion).

\subsection{Fleet gasoline consumption}

Fleet gasoline consumption can be calculated by dividing the portion of GHG emissions associated with gasoline consumption by the rate of carbon dioxide emissions associated with burning gasoline $\tau^{22}$.

$$
G=\frac{v\left(\sum_{j \in J_{\mathrm{C}}} n_{j} r_{j}^{\mathrm{G}}+\sum_{j \in J_{\mathrm{A}}} n_{j}\left(1-p_{j}\right) r_{j}^{\mathrm{G}}\right)}{\tau}
$$

Following a similar procedure, the fleet gasoline consumption $G$ is therefore:

\footnotetext{
${ }^{21}$ Technically, the emission rate for gasoline vehicles used in compliance calculations counts only combustion emissions, and the (upstream) emission rate used for alternative fuel vehicles is adjusted relative to the upstream emission rate of gasoline vehicles, but we ignore differences between these accounting approaches in our model. See Jenn et al (2016) and Federal Register v77 n199 p62822 for more details.

${ }^{22} \mathrm{We}$ use an EPA value of 11,200 grams of $\mathrm{CO}_{2} /$ gallon of gasoline (https://www.epa.gov/sites/production/files/2016-07/documents/select-ghgresults-table-v1.pdf), which includes both combustion emissions and upstream emissions related to the production of fuel (drilling, refining, and transport). We ignore diesel vehicles, since they make up a small fraction of U.S. passenger cars. We also ignore gasoline consumption in the production of vehicles and fuels.
} 


$$
G=\frac{v \delta}{\tau}\left(\bar{s} N-\sum_{j \in J_{\mathrm{A}}} n_{j} p_{j} \tilde{r}_{j}^{\mathrm{A}} w_{j}+\sum_{j \in J_{\mathrm{A}}}\left(n_{j}\left(m_{j}-1\right)\left(\bar{s}-p_{j} \tilde{r}_{j}^{\mathrm{A}} w_{j}-\left(1-p_{j}\right) \tilde{r}_{j}^{\mathrm{G}}\right)\right)\right)
$$

Here the first term inside the parentheses represents operation GHG emissions implied by the pure standard, the second term removes the weighted portion of those emissions from AFVs that are not caused by gasoline combustion (the weight $w$ accounts for increases in the conventional fleet due to the weighting incentive alone), and the third term represents additional permitted GHG emissions from the gasoline fleet due to combined weights and multipliers (if $m=1$, this term is zero). The term $\tau$ converts these gasoline-related GHG emissions into gallons of gasoline consumed.

In the following sections we first conduct simulations by computing Eq (5) and Eq (7) for the scenarios in Figure 2 using a variety of assumptions for input parameters and reporting the difference between each of the ZEV, AFVI, and BOTH scenarios and the REF scenario. We then identify a set of conditions under which Eq (5) is larger in the BOTH scenario than it is in the other scenarios.

\section{SIMULATION}

\subsection{Assumptions}

To determine emissions and gasoline consumption for the fleet in the four scenarios, we need to know the following quantities for each scenario: the fleet's GHG standard $\bar{S}$, lifetime miles traveled per vehicle $v$, the fleet's total sales volume $\sum_{j \in J} n_{j}$, the production emissions of each vehicle model $\gamma_{j}$, and the ratio of on-road energy consumption to 2-cycle laboratory test cycle energy consumption $\delta$. Additionally, for each AFV model we need to know the sales volume $n_{j} \forall j \in J_{\mathrm{A}}$, the emission rate when operating on its alternative fuel $r_{j}^{\mathrm{A}^{\prime}}$ and when operating on gasoline $r_{j}^{\mathrm{G}^{\prime}}$ (where applicable), the proportion of vehicle miles traveled operating on the alternative fuel $p_{j}$, and the difference between the real-world upstream emission rate of the alternative fuel and the value used for policy compliance calculations, $c_{j}$. We estimate each of these quantities in turn, focusing on the passenger car market because ZEV regulation has affected primarily this market. If some scenarios induce other changes, such as a change in the fleet's sales-weighted vehicle footprint or vehicle miles traveled, there could be additional effects beyond those modeled here.

\subsubsection{Vehicle sales projections}

As a base case, our results use passenger car sales projections modified from the Energy Information Administration's 2015 Annual Energy Outlook (AEO) projections through 2025. Vehicle technologies from the AEO projection include conventional vehicles, FFVs, BEVs, PHEVs, CNGVs, and FCVs. The cumulative sales projections of major AFVs for our base case are summarized in the SI. We examine a range of alternative projections in the SI and find similar qualitative conclusions.

The AEO sales projections are made assuming the presence of CAFE/GHG and ZEV policy, and they attribute a portion of projected sales to ZEV policy. For our ZEV scenarios we adopt the AEO projections. For our non-ZEV scenarios, the assumed sales volume for each AFV is modified from the original AEO sales projection (with ZEV) to remove the sales attributed to ZEV policy. The AEO provides an overall estimate of AFV sales attributed to ZEV policy, but it does not provide a breakdown for each AFV type, so we proportionally allocate the projections among all vehicle technologies, as described in the SI. In all cases the total of all fleet sales is held constant, and any changes to sales of AFVs are offset by sales to conventional vehicles (we examine alternative assumptions in the SI). We estimate $E$ from equation (5) and $G$ from equation (6) for each scenario in Figure 2 and report differences across scenarios.

Our work is not intended to model the vehicle market and produce forecasts of vehicle technology adoption. Instead, we include a sensitivity analysis that encompasses a wide range of plausible AFV adoption outcomes including forecasts based on the EIA's Annual Energy Outlook as well as alternative forecasts based on CARB projections and modified "no ZEV mandate" scenarios using historical sales for attribution as an alternative to AEO's attribution of ZEV sales. These alternative data inputs and corresponding results are discussed in the supplemental information, and we discuss robustness of our findings in the results section. 


\subsubsection{Vehicle attribute inputs}

Emission rates and the proportion of vehicle miles traveled driven on alternative fuels used in EPA compliance calculations are obtained from literature (National Center for Statistics and Analysis, 2006) and the EPA's fuel economy data ${ }^{23}$. For vehicle production emissions, we focus on differences among technologies, since the portion of production emissions common across all vehicle alternatives cancels out in all cases $\left(\gamma_{j}=\gamma+\gamma_{j}^{\prime}\right.$ where $\gamma$ is the portion of emissions common across all technologies and $\gamma_{j}^{\prime}$ is the portion specific to product $j$ ). In our numerical simulations we therefore ignore $\gamma$, and we assume the only non-negligible technology difference for production emissions $\gamma_{j}^{\prime}$ is the emissions associated with the production of batteries for plug-in electric vehicles. The values used for $\gamma_{j}^{\prime}$ for electric vehicles are formed by the high and low values found in the literature for battery production (Table S5). We use the NHTSA's technical documentation on vehicle survivability and travel mileage schedules as the basis of the average lifetime miles traveled over the lifetime of the vehicle, totaling 150,000 miles (National Center for Statistics and Analysis, 2006).

\subsubsection{On-road performance}

We estimate the ratio $\delta$ by obtaining the median of the factor increase from 2-cycle emission rates to 5-cycle emission rates for every vehicle listed in the 2015 EPA Fuel Economy Datafile ${ }^{23}$, which yields $\delta=1.31$. The sensitivity analysis encompasses the minimum factor increase of $\delta=1.17$ and the maximum factor increase of $\delta$ $=1.51$ with no major categorical average difference between conventional vehicles and electric vehicles (the only AFVs with sufficient data to compute an average $\delta$ ). No existing vehicle model in the 2015 Fuel Economy Datafile has a lower factor increase than 1.17 or a higher factor increase than 1.51. The location-related marginal emission factors for electric vehicles is important to accurately assess emissions from electric vehicles, and we adopt a range of estimates for regional marginal electricity grid emission factors summarized in Table S8 in the SI, wide enough to capture estimates from multiple studies, regions, seasons, and charge timing assumptions (Holland, Mansur, Muller, \& Yates, 2016; Zivin, Kotchen, \& Mansur, 2014; Tamayao, Michalek, Hendrickson, \& Azevedo, 2015; Yuksel, Tamayao, Hendrickson, Azevedo, \& Michalek, 2016; Archsmith, Kendall, \& Rapson, 2015). We use marginal generation mix estimates together with estimates of emissions for feedstock production emissions for coal and natural gas to produce a range of life cycle estimates associated with marginal electricity consumption (see Table S8).

\subsection{Findings}

We compute emissions across the policy scenarios using a wide range of sales projections based on data from the Energy Information Administration's 2015 Annual Energy Outlook (US Energy Information Administration, 2015) and from the California Air Resources Board as well as a wide range of assumptions for other key parameters. We find in all cases examined that fleet GHG emissions are higher for both policies together (BOTH) than for either policy alone (ZEV or AFVI). The magnitude of this increase depends on vehicle sales. Using our base case sales projections, we estimate that relative to the REF scenario (no ZEV mandate and no AFV incentives in the GHG standard), (1) adding the ZEV mandate in the presence of the GHG standard changes emissions by -16 to 61 million tons, (2) adding AFV incentives to the GHG standard increases emissions by 8 to 41 million tons, and (3) adding both policies together increases emissions by 17 to 114 million tons. Although these ranges overlap, the uncertainty for each case is correlated with the others (the same source of uncertainty affects all three estimates), and in all cases the BOTH scenario has higher emissions than the other scenarios. The largest source of uncertainty in these estimates comes from the potential for error in agency estimates of AFV upstream fuel production and distribution emissions (e.g.: electricity production emissions for plug-in vehicles), and removing that source of uncertainty substantially tightens estimates (see Figure S4 in the SI).

Figure 3 shows, for our base case sales projections, the change in estimated GHG emissions for passenger cars sold from 2012 through 2025 for each of the ZEV, AFVI, and BOTH policy cases relative to the REF case. In each case the stacked bars represent changes in each emission source under base assumptions; the dot is the net change in emissions (the sum of the stacked bars) under base assumptions; and the error bars represent uncertainty of the net change in emissions due to (1) uncertainty in electricity production and vehicle production emissions and their measurement by the agency, (2) uncertainty in actual on-road vehicle efficiency relative to laboratory test efficiency

${ }^{23}$ US Department of Energy and US Environmental Protection Agency, Fuel Economy Datafiles. https://www.fueleconomy.gov/feg/download.shtml 
used for compliance calculations (represented as the difference between five-cycle and two-cycle laboratory tests), and (3) uncertainty of AFV sales induced by AFV incentives. In particular, while our sales projection data sources make sales projections in the presence of both policies and identify the portion of sales attributable to ZEV policy, they do not identify sales attributable to the GHG standard's AFV incentives. As a point estimate, we show the case where AFV sales induced by AFV incentives are half of the non-ZEV sales, and our uncertainty range captures the full range of assumptions from $0 \%$ to $100 \%$ of the non-ZEV sales. Details are provided in the supplemental information. In each case the error bars are calculated by combining all possible combinations of high and low estimates for each parameter.

- The first column shows the change in emissions for the ZEV case relative to the REF case. The ZEV mandate results in increased sales of AFVs in place of conventional vehicles, but the emissions from AFVs offset the savings from displaced conventional vehicles. The operation-related emissions cancel exactly when the agency estimates of upstream emissions are correct, and the net effect (represented by a dot) is near zero under the binding GHG standard using base assumptions (falling just above zero largely due to differences in vehicle manufacturing emissions not captured in the scope of the federal GHG standard). The uncertainty range from -16 to 61 million tons $\mathrm{CO}_{2}$ is primarily a result of uncertainty in the potential for agency error in estimating upstream AFV emissions (if the EPA estimates upstream electric vehicle emissions as higher than they actually are, then the effective standard for the remainder of the fleet is reduced and net emissions can decrease as AFV sales increase). Figure S4 in the supplemental information repeats Figure 3 with the uncertainty of agency upstream AFV emissions estimation error removed, resulting in a much smaller uncertainty range entirely above zero.

- The second column shows the change in emissions for the AFVI case relative to the REF case. Adding AFV incentives relaxes the fleet GHG standard for every AFV sold. Automakers responding to this constraint relaxation sell a higher-emitting conventional vehicle fleet as a result, producing a cumulative lifetime increase of 29 [8 to 41] million tons of $\mathrm{CO}_{2}$ for vehicles sold from 2012 through 2025. FFVs cause a larger effect than plug-in vehicles because of the volume sold.

- The last column shows the change in emissions for the BOTH case relative to the REF case. The ZEV mandate induces AFV sales, which displace conventional vehicle sales, but the AFV incentives relax the GHG standard for the remainder of the fleet every time an AFV is sold, so the overall standard is less stringent, and the resulting fleet is a higher-emitting fleet. The net effect is an increase in GHG emissions of 81 [ 17 to 114 ] million tons. This represents an average of 0.73 [0.15 to 1.0 ] tons per vehicle sold and about $2 \%[0.4 \%$ to $2.8 \%]$ of the overall GHG reductions estimated from CAFE/GHG policy.

Even under our conservative uncertainty bounds, our primary finding is robust: The combination of ZEV policy and $\mathrm{CAFE} / \mathrm{GHG} \mathrm{AFV}$ incentives leads to an increase in emissions relative to either policy alone. ${ }^{24}$ In the supplemental information, we also repeat this analysis with three other sources of sales projections and observe this finding to be robust - though the magnitude of the effect depends on sales, and estimated emissions could conceivably be higher or lower if the future sales of AFVs fall outside the range of sales projections used in our sensitivity analysis.

\footnotetext{
${ }^{24}$ The error bars are correlated because some sources of uncertainty affect all three estimates simultaneously. We separately verify that the BOTH scenario has higher emissions than the other scenarios in all combinations of values for the uncertain parameters.
} 


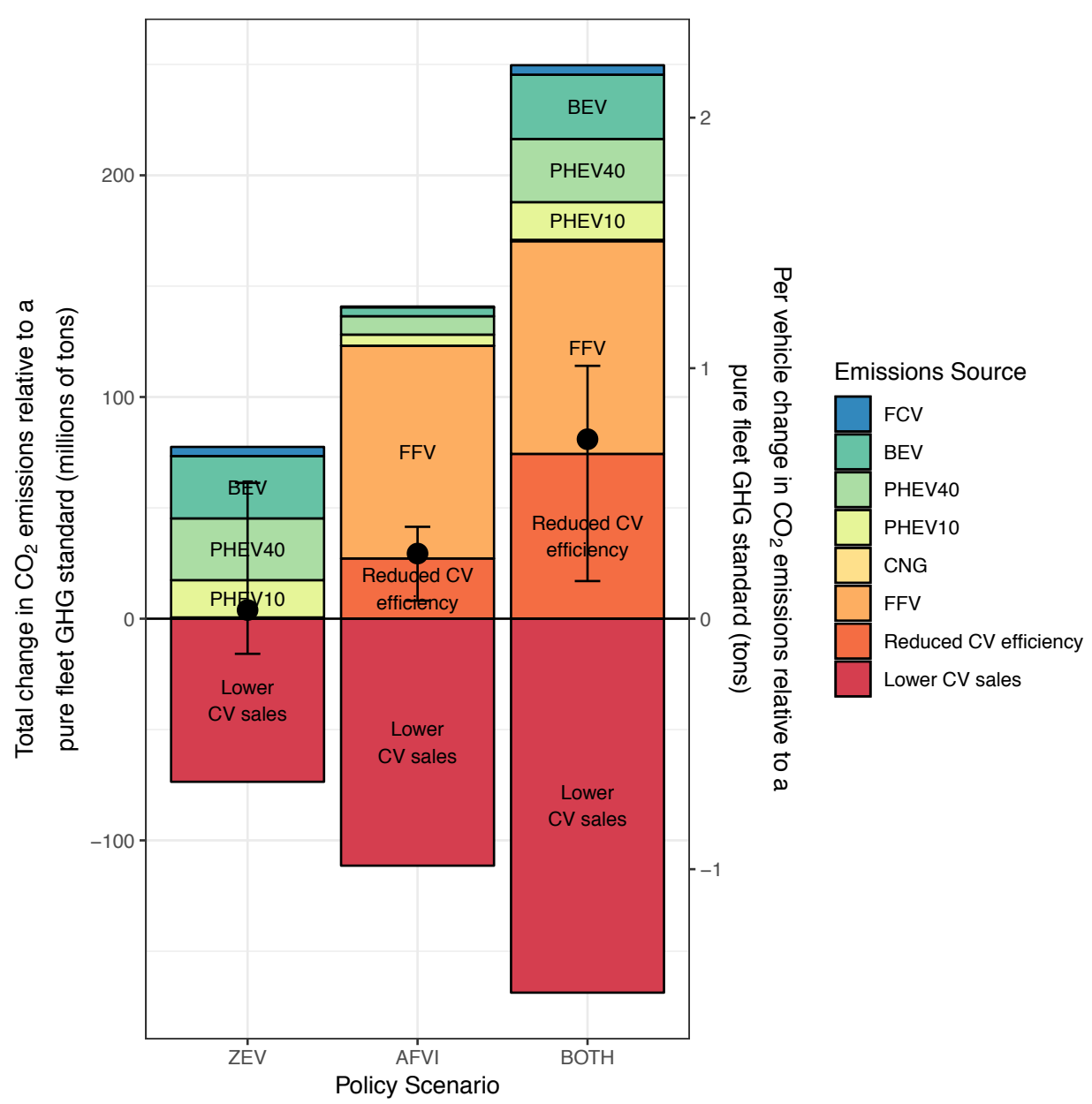

Figure 3: Total change in life cycle emissions for the fleet of model year 2012 through 2025 passenger cars relative to a baseline scenario of pure light-duty fleet GHG standards (with no AFV incentives or mandates). AFVI refers to the AFV incentives in federal light-duty fleet GHG emission standards. Dots indicate the net change in emissions, and the error bars capture the interval of uncertainty for differences in electricity and vehicle production emissions and their measurement by the agency, on-road vs. laboratory compliance test vehicle efficiency, and AFV sales induced by AFV incentives. The secondary axis converts total change in emissions to average change per passenger car sold for scale.

Figure 4 similarly shows, for the same set of sales projections and uncertainty ranges, the change in estimated gasoline consumption for passenger cars sold from 2012 through 2025 for the ZEV, AFVI, and BOTH policy cases relative to the REF case. In the first column, adding the state ZEV mandate results in a total change of -22 billion gallons of gasoline consumption when compared to the base case, as conventional vehicles are displaced by AFVs that consume less gasoline. However, the uncertainty, due primarily to uncertainty about sales induced by the AFV incentives, is relatively large: from -30 to -11 billion gallons. In the second column, adding AFV incentives increases AFV sales an uncertain amount but relaxes the fleet standard for every AFV sold. Automakers responding to this constraint relaxation sell less efficient conventional vehicles as a result, producing a net change of about -10 $[-20$ to +2.8$]$ billion gallons of gasoline consumed. In the last column, the ZEV mandate forces AFV sales in place of conventional vehicle sales, and the AFV incentives relax the binding fleet GHG standard, so the remaining conventional fleet is a less efficient fleet. The effect on gasoline consumption of switching from conventional vehicles to AFVs is larger than the effect of the reduced efficiency of the remaining conventional fleet, so the net effect is a change of about -15 [-24 to -3] billion gallons of gasoline consumed from vehicles sold from 2012 to 2025. This represents -130 [-171 to -33$]$ gallons per vehicle and about $5.5 \%$ [ $6.2 \%$ to $0.3 \%$ ] of the overall gasoline consumption reductions estimated from $\mathrm{CAFE} / \mathrm{GHG}$ policy during this period. 
We also conduct an additional scenario extending the AFV credits in 2020 through to $2025^{25}$ to represent a potential change to the GHG regulations proposed by the Trump administration (along with a freeze of the standards themselves). We find that with extended AFV credits, the combination of AFV policies (BOTH) results in a point estimate of 94 million tons more $\mathrm{CO}_{2}$ than the reference case (a 13 million ton larger increase than in our base case). Details are presented in the SI $\S 3.7$.

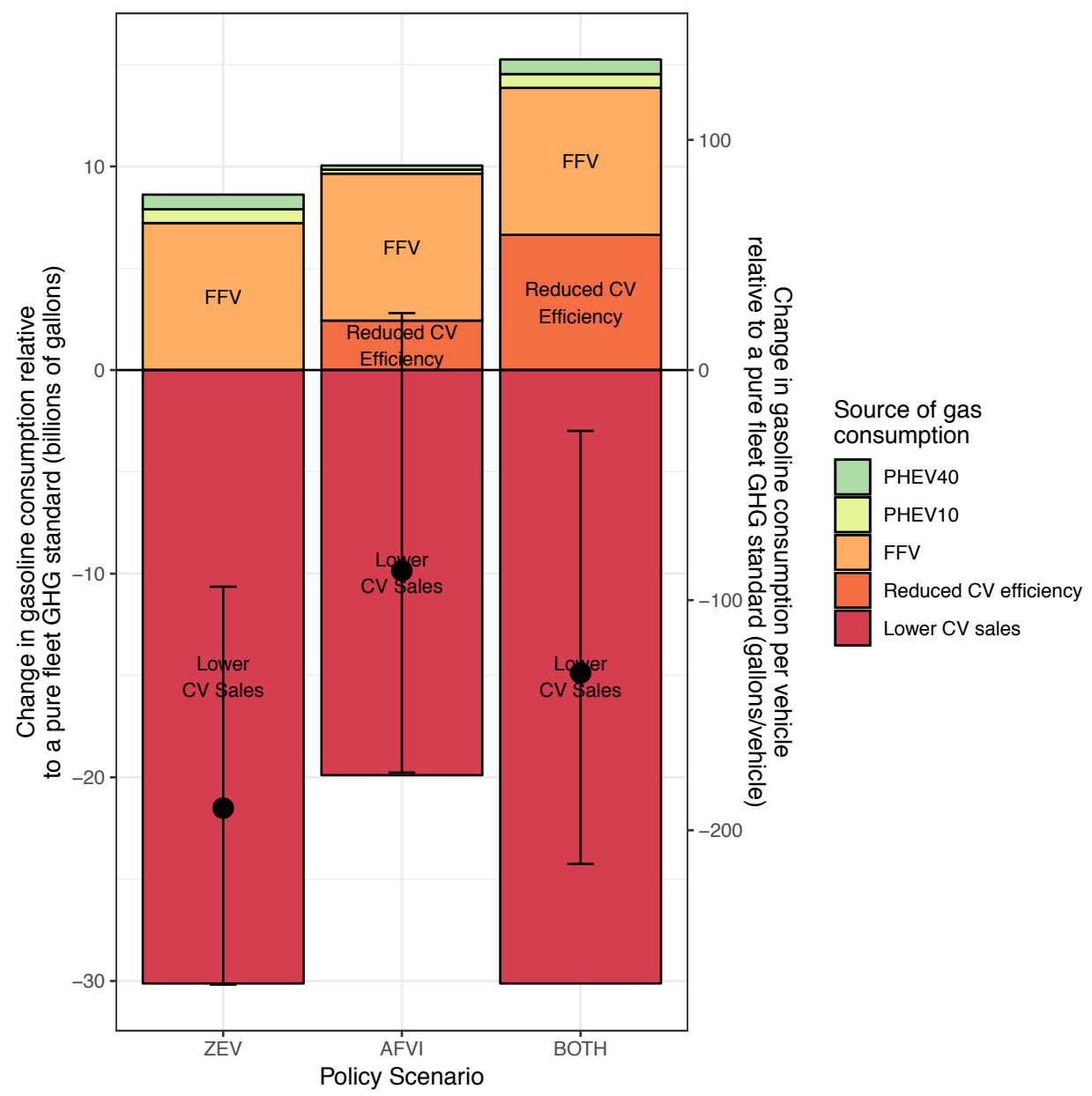

Figure 4: Change in total gasoline consumption for the fleet of model year 2012 through 2025 passenger cars relative to a baseline scenario with pure light-duty fleet GHG standards (no AFV incentives or ZEV mandate). AFVI refers to the AFV incentives in federal light-duty fleet GHG emission standards. Dots indicate the net change in gasoline consumption, and the error bars capture the interval of uncertainty for differences in electricity and vehicle production emissions and their measurement by the agency, on-road vs. laboratory compliance test vehicle efficiency, and AFV sales induced by AFV incentives. The secondary axis converts total change in emissions to average change per passenger car sold for scale.

\section{ANALYSIS OF SUFFICIENT CONDITIONS}

One potential critique of our simulation results is that, despite the wide range of sensitivity cases tested, a different set of assumptions about future fleet sales mix, vehicle emission rates, grid emission rates, or other factors could lead to a different finding. To further characterize the robustness of our results, we identify a set of assumptions sufficient to prove that GHG emissions are higher in the BOTH policy scenario than in the ZEV or AFVI scenarios

\footnotetext{
${ }^{25}$ Federal Register Vol. 83, No. 165 “The Safer Affordable Fuel-Efficient Vehicles Rule for Model Years 2021-2026 Passenger Cars and Light Trucks". pp 43461
} 
alone. To do this, we apply Eq. (5) to the four policy scenarios in Figure 2 and write expressions for the differences between scenarios (see SI §2). We examine the resulting equations and identify a set of conditions under which the net emissions in the BOTH scenario are larger than in the ZEV, AFVI, and REF scenarios. The conditions are:

(1) Incentives Increase Sales: ZEV policy and AFV incentives each increase sales of at least some AFVs and do not reduce sales of any AFVs;

(2) AFV Operation Emissions: AFVs have lower use-phase emissions than the fleet average vehicle;

(3) AFV Production Emissions: AFV production emissions are comparable to or potentially higher than conventional vehicle production emissions, and

(4) Agency Grid Emissions Estimates: agency estimates of upstream fuel production emissions are accurate or potentially optimistic.

In the Supplemental Information, we summarize evidence that each of these conditions holds in practice. The identified conditions are sufficient to show that GHG emissions are larger in the BOTH scenario than in the other scenarios, but they are not necessary - i.e.: there exist more general conditions under which our conclusions hold, but the stated conditions are sufficient and easy to understand. Some degree of violation of these conditions can be tolerated without changing our conclusions. Mathematical details are provided in the Supplemental Information.

Under these conditions, we identify three findings:

Finding 1: ZEV policy increases emissions. Adding ZEV policy to a pure GHG standard results in higher emissions than under the pure GHG standard alone.

Finding 2: AFV incentives increase emissions. Adding AFV incentives to a pure GHG standard results in higher emissions than under the pure GHG standard alone.

Finding 3: Combining policies increases emissions. The combined effect of ZEV policy and AFV incentives together results in higher GHG emissions than under the ZEV policy alone or the AFVI policy alone.

As described previously, our model assumes that the automotive industry sells the highest-emitting fleet permitted (in order to obtain other things like lower cost or higher performance), and the policy changes examined do not induce changes to automakers' GHG standards (other than the AFV incentives themselves), such as causing changes in vehicle footprint. In the Supplemental Information we summarize evidence that this assumption holds.

Additionally, our model also assumes fixed VMT per vehicle across the fleet, and our model assumes that while the policies in question may affect vehicle design or sales mix, they do not affect the total number of new vehicles sold. While total new vehicle sales could potentially be affected by these AFV policies in practice (Jacobsen \& Benthem, 2015), it is difficult to credibly model net emissions implications from changes in new vehicle sales without also modeling induced changes in the used car market, transit, and other sectors, introducing substantial uncertainty. Instead, we conduct sensitivity analysis to observe how much total new vehicle sales could change without altering our qualitative results for the new car fleet, and we find that our key finding holds if the combined policies (BOTH) do not reduce new vehicle sales by more than $1 \%$ relative to sales under either policy alone (ZEV or AFVI) (see SI $\S 3)$.

\section{DISCUSSION}

We find that in the presence of federal fleet GHG standards, interactions between federal and state AFV adoption policies lead to increased fleet greenhouse gas emissions relative to either AFV policy alone. The primary goal of federal light-duty GHG standards is to reduce near-term GHG emissions from the fleet, and prior analysis shows that it accomplishes this goal, albeit inefficiently. In contrast, the primary goal of both state ZEV policy and of federal AFV incentives in the GHG standards is to develop a market for AFVs and help enable a long-term fleet technology transition. We show that pure GHG standards (without AFV incentives) together with ZEV policy can potentially make progress toward these individual goals without a negative influence on one another. However, the AFV incentives in federal GHG standards, which allow automakers that sell AFVs to meet less stringent fleet emissions standards, produce net increases in fleet emissions that are compounded under ZEV policy. While state 
ZEV policy and federal GHG AFV incentives are both intended to encourage AFV sales and spur technology development and market acceptance toward a long-term fleet transition, the ZEV policy can potentially achieve this goal without significant increases to near-term GHG emissions, whereas the AFV incentives increase net GHG emissions, and the combination of the two policies further increases net emissions. If the goals of the federal and state policy are to reduce GHG emissions and gasoline consumption while encouraging AFV sales, the policies would produce better outcomes if AFV incentives were removed from GHG standards, decoupling the two goals and allowing ZEV objectives to be pursued without a significant effect on GHG goals. Of course, other factors, such as the effect of more stringent GHG standards on industry and employment, implications for congestion or conventional air pollution, effects of innovation and technology development, and effects on the used car market should be considered as well when making such policy decisions (Parry, Walls, \& Harrington, 2007). The different jurisdictions and regulatory authorities under which these policies are currently implemented also poses challenges for policy coordination. As long as the AFV incentives for the federal GHG standard are in place (planned at least through 2025), states considering adopting California's ZEV program should consider the effect that federal and state policy interactions will have on U.S. fleet emissions and gasoline consumption.

\section{ACKNOWLEDGEMENTS}

We thank Roberts French and Jeff Alson from the U.S. EPA, John Whitefoot from NHTSA, Rick Gazelle and William Chernicoff from Toyota Motor North America, and Andrew Yates from the University of North Carolina, Chapel Hill for their assistance in understanding CAFE and GHG emission standards regulations. We also thank Anna Wong and Analise Bevan for assistance in understanding the ZEV regulation. This work was funded in part by the Center for Climate and Energy Decision-Making (SES-0949710 and SES-1463492) through a cooperative agreement between the National Science Foundation and Carnegie Mellon University, by Toyota Motor Corporation, and by the Bertucci Fellowship at Carnegie Mellon University. The views expressed are those of the authors and not necessarily those of the sponsors.

\section{BIBLIOGRAPHY}

Allcott, H., \& Wozny, N. (2014). Gasoline prices, fuel economy, and the energy paradox. Review of Economics and Statistics, 96(5), 779-795.

Anderson, M. L., \& Auffhammer, M. (2013). Pounds that kill: The external costs of vehicle weight. Review of Economic Studies, 81(2), 535-571.

Archsmith, J., Kendall, A., \& Rapson, D. (2015). From cradle to junkyard: assessing the life cycle greenhouse gas benefits of electric vehicles. Research in Transportation Economics, 52, 72-90.

Austin, D., \& Dinan, T. (2005). Clearing the air: The costs and consequences of higher CAFE standards and increased gasoline taxes. Journal of Environmental Economics and Management, 50(3), 562-582.

Bastani, P., Heywood, J. B., \& Hope, C. (2012). US CAFE Standards.

Brown, M. B., Canzler, W., Fischer, F., \& Knie, A. (1995). Technological Innovation through Environmental Policy: California's Zero-Emission Vehicle Regulation. Public Productivity \& Management Review, 19(1), 77-93.

Busse, M. R., Knittel, C. R., \& Zettelmeyer, F. (2013). Are Consumers Myopic? Evidence from New and Used Car Purchases. American Economic Review, 103(1), 220-256.

Collantes, G., \& Sperling, D. (2008). The origin of California's zero emission vehicle mandate. Transportation Research Part A, 42, 1302-1313.

Cunningham, J. (2010). Achieving an 80\% GHG Reduction by 2050 in California's Passenger Vehicle Fleet: Implications for the ZEV Regulation. SAE International.

Davis, L. W., \& Knittel, C. R. (2016). Are Fuel Economy Standards Regressive? National Bureau of Economic Research.

Dunn, J., Gaines, L., Barnes, M., Wang, M., \& Sullivan, J. (2012). Material and energy flows in the materials production, assembly, and end-of-life stages of the automotive lithium-ion battery life cycle. Argonne National Labs.

Gecan, R. (2012). Effects of Federal Tax Credits for the Purchase of Electric Vehicles. US Congressional Budget Office.

Goulder, L. H., \& Stavins, R. N. (2011). Challenges from state-federal interactions in US climate change policy. The American Economic Review, 101(3), 253-257.

PRE-PRINT

Use published version for citation: https://www.sciencedirect.com/science/article/pii/S0965856417311436 
Goulder, L. H., Jacobsen, M. R., \& Van Benthem, A. A. (2012). Unintended consequences from nested state and federal regulations: The case of the Pavley greenhouse-gas-per-mile limits. Journal of Environmental Economics and Management, 63(2), 187-207.

Goulder, L. H., Parry, I. W., Williams, R. C., \& Burtraw, D. (1999). The cost-effectiveness of alternative instruments for environmental protection in a second-best setting. Journal of Public Economics, 72(3), 329360.

Granovskii, M., Dincer, I., \& Rosen, M. A. (2006). Economic and environmental comparison of conventional, hybrid, electric and hydrogen fuel cell vehicles. Journal of Power Sources, 159(2), 1186-1193.

Hart, K., Curran, M. A., Davies, C., Meyer, D. E., Gaines, L., Dunn, J., . . Helou, C. (2013). Lithium-Ion Batteries and Nanotechnology for Electric Vehicles: A Life Cycle Assessment. US Environmental Protection Agency.

Holland, S. P. (2012). Emissions taxes versus intensity standards: Second-best environmental policies with incomplete regulation. Journal of Environmental Economics and Management, 63(3), 375-387.

Holland, S. P., Mansur, E. T., Muller, N. Z., \& Yates, A. J. (2016). Are there environmental benefits from driving electric vehicles? The importance of local factors. American Economic Review, 106(12), 3700-3729.

Jacobsen, M. R. (2013). Evaluating US Fuel Economy Standards in a Model with Producer and Household Heterogeneity. American Economic Journal: Economic Policy, 5(2), 148-187.

Jacobsen, M. R. (2013). Fuel Economy and Safety: The Influences of Vehicle Class and Driver Behavior. American Economic Journal: Applied Economics, 5(3), 1-26.

Jacobsen, M. R., \& Benthem, A. A. (2015). Vehicle Scrappage and Gasoline Policy. American Economic Review, 105(3), 1312-1338.

Jenn, A., Azevedo, I. M., \& Michalek, J. J. (2016). Alternative fuel vehicle adoption increases fleet gasoline consumption and greenhouse gas emissions under United States Corporate Average Fuel Economy policy and Greenhouse Gas Emissions Standards. Environmental Science \& Technology, 50.5, 2165-2174.

Karplus, V., \& Paltsev, S. (2012). Proposed vehicle fuel economy standards in the United States for 2017 to 2025 : impacts on the economy, energy, and greenhouse gas emissions. Transportation Research Record: Journal of the Transportation Research Board, 2287, 132-139.

Klier, T., \& Linn, J. (2012). New-vehicle characteristics and the cost of the Corporate Average Fuel Economy standard. The RAND Journal of Economics, 43(1), 186-213.

Linn, J. (2016). The Rebound Effect for Passenger Vehicles. The Energy Journal, 37(2).

Majeau-Bettez, G., Hawkins, T. R., \& Stromman, A. H. (2011). Life cycle environmental assessment of lithium-ion and nickel metal hydride batteries for plug-in hybrid and battery electric vehicles. Environmental Science \& Technology, 45(10), 4548-4554.

Morrow, W. R., Gallagher, K. S., Collantes, G., \& Lee, H. (2010). Analysis of policies to reduce oil consumption and greenhouse-gas emissions from the US transportation sector. Energy Policy, 38(3), 1305-1320.

National Center for Statistics and Analysis. (2006). Vehicle Survivability and Travel Mileage Schedules. National Highway Traffic Safety Administration. Washington DC: US Department of Transportation.

Notter, D. A., Gauch, M., Widmer, R., Wager, P., Stamp, A., Zah, R., \& Althaus, H.-J. (2010). Contribution of Liion batteries to the environmental impact of electric vehicles. Environmental Science \& Technology, 44(17), 6550-6556.

O'Rear, E. G., Sarica, K., \& Tyner, W. E. (2015). Analysis of impacts of alternative policies aimed at increasing US energy independence and reducing GHG emissions. Transport Policy, 37, 121-133.

Parry, I., Walls, W. M., \& Harrington, W. (2007). Automobile Externalities and Policies. Journal of Economic Literature, 45(2), 373-399.

Portney, P. R., Parry, I. W., Gruenspecht, H. K., \& Harrington, W. (2003). The Economics of Fuel Economy Standards. Resources for the Future, Washington, DC.

Renaert, M. (2014). Abatement Strategies and the Cost of Environmental Regulation: Emission Standards on the European Car Market. KU Leuven Center for Economic Studies.

Sarica, K., \& Tyler, W. (2012). Alternative policy impacts on US GHG emissions and energy security: A hybrid modeling approach. Energy Economics, 40, 40-50-.

Sperling, D., \& Eggert, A. (2014). California's climate and energy policy for transportation. Energy Strategy Reviews, 5, 88-94.

Tamayao, M.-A. M., Michalek, J., Hendrickson, C., \& Azevedo, I. (2015). Regional Variability and Uncertainty of Electric Vehicle Life Cycle CO2 Emissions across the United States. Environmental Science \& Technology, 49.14, 8844-8855.

US Energy Information Administration. (2015). Annual Energy Outlook 2015 with projections to 2040. US Energy Information Administration, Department of Energy, Washington DC. 
611

612

613

614

615

616

617

618

619

620

621

622

623

624

625

626

627

Wesseling, J., Farla, J., \& Hekkert, M. (2015). Exploring car manufacturers' responses to technology-forcing regulation: The case of California's ZEV mandate. Environment Innovation and Societal Transitions, 16, $87-105$

Wesseling, J., Farla, J., Sperling, D., \& Hekkert, M. (2014). Car manufacturers' changing political strategies on the ZEV mandate. Transportation Research Part D, 33, 196-209.

Witt, M., Bomberg, M., Lipman, T., \& Williams, B. (2012). Plug-In Electric Vehicles in California: Review of Current Policies, Related Emissions Reductions for 2020, and Policy Outlook. Transportation Research Record: Journal of the Transportation Research Board, 155-162. doi:10.3141/2287-19

Yuksel, T., Tamayao, M.-A., Hendrickson, C., Azevedo, I. L., \& Michalek, J. (2016). Effect of regional grid mix, driving patterns and climate on the comparative carbon footprint of gasoline and plug-in electric vehicles in the United States. Environmental Research Letters, 11.

Zackrisson, M., Avellan, L., \& Orlenius, J. (2010). Life cycle assessment of lithium-ion batteries for plug-in hybrid electric vehicles--Critical issues. Journal of Cleaner Production, 18(15), 1519-1529.

Zivin, J. S., Kotchen, M. J., \& Mansur, E. T. (2014). Spatial and temporal heterogeneity of marginal emissions: Implications for electric cars and other electricity-shifting policies. Journal of Economic Behavior \& Organization, 107, 248-268. 


\section{SUPPLEMENTAL INFORMATION}

\section{EXPANDED BACKGROUND}

\subsection{CAFE and ZEV policy details}

In Table S1, we provide the parameter values for the alternative fuel vehicle (AFV) incentives in the GHG emission standards in 2012 through 2025.

Table S1: Summary of federal GHG AFV Incentives from 2012 to $2025 \ldots 1$,2

\begin{tabular}{|c|c|c|c|c|c|c|c|c|}
\hline \multirow[b]{2}{*}{$\frac{0}{\frac{0}{0}} \stackrel{0}{\infty}$} & \multirow[b]{2}{*}{ 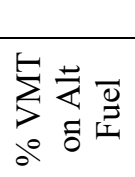 } & \multicolumn{5}{|c|}{ Multiplier } & \multicolumn{2}{|c|}{ Weighting Factor } \\
\hline & & $\stackrel{\dot{\sim}}{\stackrel{ }{\circ}} \stackrel{0}{\circlearrowright}$ & 승 & ণి & 공 & ત่̃ & 서유 을 & 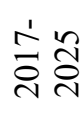 \\
\hline $\mathrm{CV}$ & $0 \%$ & 1.0 & 1.0 & 1.0 & 1.0 & 1.0 & 1.0 & 1.0 \\
\hline FFV & $15 \%{ }^{3}$ & 1.0 & 1.0 & 1.0 & 1.0 & 1.0 & 0.15 & 1.0 \\
\hline $\mathrm{CNG}$ & $100 \%$ & 1.0 & 1.6 & 1.45 & 1.3 & 1.0 & 1.0 & 1.0 \\
\hline $\mathrm{BEV}$ & $100 \%$ & 1.0 & 2.0 & 1.75 & 1.5 & 1.0 & 0 & 0 \\
\hline PHEV & $29-66 \%$ & 1.0 & 1.6 & 1.45 & 1.3 & 1.0 & 0 & 0 \\
\hline $\mathrm{FCV}$ & $100 \%$ & 1.0 & 2.0 & 1.75 & 1.5 & 1.0 & 0 & 0 \\
\hline
\end{tabular}

The EPA determines the portion of vehicle miles traveled (VMT) assumed to be propelled by the alternative fuel, and we use their numbers to maintain consistency with the compliance calculations for fuel efficiency/emissions rates. For flex-fuel vehicles (FFVs), the weighting factor expired at the end of 2014 and cannot exceed $1.2 \mathrm{MPG}$ average increase per manufacturer. Similarly, from 2012 through 2016 battery electric vehicles (BEVs) and fuel cell vehicles (FCVs) have a cumulative production cap limit of 200,000 vehicles per manufacturer unless 25,000 vehicles of a technology are sold in 2012, which raises the cumulative cap to 300,000 vehicles. For the 2012 to 2016 provisions, there is a sales cap for AFV incentives of 200,000 BEVs, FCVs, and plug-in hybrid electric vehicles (PHEVs) in 2022 through 2025 unless there are cumulative sales of 300,000 BEVs, FCVs, and PHEVs in 2019 through 2021 whereupon the sales cap is raised to 300,000 in the latter half of the standards program. ${ }^{1,2}$ None of our sales projections exceed these caps.

The ZEV mandate requirements are summarized in Table S2, which shows the overall ZEV sales share mandate for large vehicle manufacturers. The most recent plan is described in greater detail in Table S3 with breakdown by technologies as described in the main report. The four vehicle categories are: ZEVs (FCVs and BEVs), transitional partial-ZEVs (TZEVs: PHEVs and dual-fuel FCVs), AT-PZEVs (HEVs, compressed natural gas vehicles (CNGVs), and methanol FCVs), and PZEVs (extremely clean conventional vehicles). Automakers receive credits that are used to fulfill a requirement quota based on the total number of vehicles sold in California and other Section 177 states. The credit amounts are based on the vehicle technology as well as a number of bonuses.

\footnotetext{
1 Section C: Additional Credit Opportunities for $\mathrm{CO}_{2}$ Fleet Average Program, Subsection 2: Flexible Fuel and Alternative Fuel Vehicle Credits. Federal Register Vol. 75, No. 88 2 Subsection 3: Advanced Technology Vehicle Incentives for Electric Vehicles, Plug-in Hybrids, and Fuel Cell Vehicles. Federal Register Vol. 77, No. 199.

${ }^{3}$ Beginning in MY2017 the procedure for determining the portion of FFV travel propelled by ethanol was changed. However, since FFVs were no longer incentivized after 2016 (weights and multipliers were set to 1), the change does not affect our calculations. After MY2017 FFVs are no longer part of the incentivized AFV fleet and effectively become part of the remainder of the fleet that is assumed to adjust so that the fleet complies exactly with the GHG standard.
} 
Table S2: Early California Air Resources Board Zero Emissions Vehicles Program4. Percentages describe the required proportion of sales of zero emissions vehicles by all manufacturers.

\begin{tabular}{ccccccccc}
\hline Year & $1998-2000$ & 2001 & 2003 & $2005-2008$ & $2009-2011$ & $2012-2014$ & $2015-2017$ & $2018+$ \\
\hline 1990 Plan & $2 \%$ & $5 \%$ & $10 \%$ & - & - & - & - & - \\
1996 Plan & - & - & $10 \%$ & - & - & - & - & - \\
2001 Plan & - & - & $10 \%$ & $10 \%$ & $11 \%$ & $12 \%$ & $14 \%$ & $16 \%$ \\
2009 Plan & - & - & - & - & - & Table S3* & Table S3* &
\end{tabular}

* - After 2001, ZEV requirements became more complicated, as mandates included a mix of different ZEV and partial ZEV types and manufacturers were permitted alternative paths to compliance.

Table S3: CARB ZEV requirements from 2012 to 2017 by percentage of total sales5.

\begin{tabular}{c|c|c|c|c}
\hline \multicolumn{2}{c}{$2012-2014$} & \multicolumn{2}{c}{$2015-2017$} \\
\hline Vehicle Category & Compliance $\%$ & Credits & Compliance \% & Credits \\
\hline PZEV & $6 \%$ & .2 & $6 \%$ & 0 \\
AT-PZEV & $3 \%$ & $"+$ AC + LFC & $2 \%$ & 0 \\
TZEV & $2.21 \%$ & $("+$ ZVMT)*EIM & $3 \%$ & 0 \\
ZEV & $0.79 \%$ & $2-7$ & $3 \%$ & $2-3$
\end{tabular}

AC - Advanced Components Allowance, LFC - Low Fuel Cycle Allowance, ZVMT - Zero Emissions VMT, EIM - Early Intro Multiplier.

\subsection{Extended literature overview}

\subsubsection{Studies of CAFE (pre-2012)}

In an early overview of the CAFE standards, Greene penned a strong advocacy for the policy, arguing for its success on the metrics of economic efficiency, fuel economy and fuel savings, and public perception. His study estimates some quantifiable benefits of the policy, including 45 billion gallons of gasoline savings per year associated with a $\$ 55$ billion annual savings in gasoline costs, even when taking into account a potential $20 \%$ rebound effect (Greene 1998).

In a study on the effect of changing the CAFE regulation, Kleit examines the effect of increasing the standards by 3 MPG and estimates a welfare loss of $\$ 4$ billion per year, though this is associated with the annual savings of 5.2 billion gallons of gasoline (Kleit 2004). Gerard and Lave argue that the results of Kleit's work is an indication that consumers choose vehicles that are inconsistent with social preferences for fuel conservation and that internalizing externalities associated with safety, congestion, air pollution, greenhouse gas emissions, and national security are critical to mitigating market distortions. Their work advocates for a minimum gasoline tax of $\$ 1.50$ per gallon in addition to the CAFE program itself in order to meet the social benefits argued by CAFE critics (Gerard and Lave 2003). Also following up on Kleit's work, Austin and Dinan model a 3.8 mpg increase in the standards using assumptions of consumer preferences and technology costs (rather than Kleit's gas tax elasticity). They likewise argue against the economic inefficiency of the policy, preferring a gasoline tax mechanism (Austin and Dinan 2005).

Foreshadowing the CAFE changes in 2009, Bezdek and Wendling examine the potential impacts of changes to the policy under a "business-as-usual" (same), "moderate" (27.5 to $33 \mathrm{mpg}$ from 2005 to 2010), and "advanced" ( 27.5 to $35.75 \mathrm{mpg}$ by 2010 and to $41.25 \mathrm{mpg}$ by 2015 ) scenarios. The "advanced" scenario is more aggressive than the changes that were implemented in 2012. While their work is focused on economic impacts, particularly job creation, they find that the enhanced standards could annually reduce oil consumption by 30 billion gallons, save drivers $\$ 40$ billion, and reduce GHG emissions by 100 million tons (Bezdek and Wendling 2005).

4 Energy Information Administration: California Low Emission Vehicle Program and Carbon Standard for LightDuty Vehicles, http://www.eia.gov/oiaf/archive/aeo04/leg_reg3.html 5 Zero-Emission vehicle standards for 2009 through 2017 model year passenger cars, light-duty trucks, and mediumduty vehicles. California Air Resources Board. https://www.arb.ca.gov/msprog/zevprog/zevregs/1962.1_Clean.pdf 


\subsubsection{Other CAFE effects}

The flex fuel vehicle incentive was one of the earliest incentives in CAFE and was first introduced in 1988 under the Alternative Motor Fuels Act (AMFA). In a joint report to Congress by the Department of Transportation, Department of Energy, and the EPA, the AMFA was found to successfully introduce 1.2 million FFVs. However, they also show that of 176,000 gasoline stations available, only 121 offered E85 fuel and the vast majority of FFVs simply used gasoline as their primary fuel (US Department of Transportation 2002). In a separate study by Liu and Helfand, a theoretical framework shows that under AMFA, emissions can actually increase under certain conditions, particularly by increasing production of fuel inefficient vehicles (Liu and Helfand 2009). A further study by Whistance and Thompson examining AMFA's effects determined that even with an extension through 2025 and high elasticity values, the demand for biofuels barely exceeds the requirements from the Renewable Fuel Standards regulation (Whistance and Thompson 2014). Incidentally, the FFV incentives actually provided a mechanism with which to understand the costs of compliance with the CAFE standards. Anderson and Sallee estimate the cost that manufacturers face when installing a flex-fuel system and equating it to the marginal cost of compliance, finding a \$9-\$27 cost for a one mpg increase (Anderson and Sallee 2011).

CAFE has also been shown to affect manufacturers' vehicle design decisions. Strategies to improve fuel efficiency can range from reducing rolling resistance in the tires to a complete overhaul of the vehicle structure and frame. In addition, with the introduction of the footprint-based standard in 2012, the sizing of the vehicle has become an additional decision parameter for manufacturers to use. As a result of the switch to an attribute-based structure, McManus finds that CAFE favors American automakers, as the relative size of their vehicles allows for a more relaxed standard. By simulating and projecting future fleets for each of the manufacturers, the difference in compliance values can be as high as $6 \mathrm{mpg}$ (McManus 2007). Strategies for automakers responding to CAFE can include increasing vehicle size (Whitefoot and Skerlos 2012), employing tradeoffs in power and weight versus fuel efficiency (Klier and Linn 2012), or even paying penalties rather than complying with the standard (Shiau, Michalek and Hendrickson 2009). While not directly the same as CAFE, the European emission standards have also been shown to induce behavior among firms by changing relative pricing, downsizing the fleet, or by adopting new technology (Reynaert 2014).

\section{DERIVATION OF SUFFICIENCY CONDITIONS}

In this section we derive expressions for the difference in net emissions between all pairs of policy scenarios examined in the main document and establish conditions under which these differences are positive.

\subsection{General Case:}

In the general case, net emissions (Eq.(5) in the main text) are:

$$
E=\delta v\left(\bar{s} \sum_{j \in J} n_{j}+\sum_{j \in J_{A}} n_{j} p_{j} c_{j}+\sum_{j \in J_{A}} n_{1 j}\left(\left(1-m_{j} w_{j}\right) p_{j} r_{j}^{A^{\prime}}+\left(m_{j}-1\right)\left(\bar{s}-\left(1-p_{j}\right) r_{j}^{G^{\prime}}\right)\right)\right)+\sum_{j \in J} n_{j} \gamma_{j}
$$

For any two policy scenarios, assuming the overall standard $\bar{s}$ is constant (which holds if policy changes do not induce changes to the sales-weighted average vehicle footprint or the car vs. truck sales mix):

Policy Scenario 1:

$$
\begin{aligned}
E_{1}=\delta v\left(\bar{s} \sum_{j \in J} n_{1 j}\right. & \left.+\sum_{j \in J_{A}} n_{1 j} p_{j} c_{j}+\sum_{j \in J_{A}} n_{1 j}\left(\left(1-m_{1 j} w_{1 j}\right) p_{j} r_{j}^{A^{\prime}}+\left(m_{1 j}-1\right)\left(\bar{s}-\left(1-p_{j}\right) r_{j}^{G^{\prime}}\right)\right)\right) \\
& +\sum_{j \in J} n_{1 j} \gamma_{j}
\end{aligned}
$$

Policy Scenario 2: 
100

101

102

$$
\begin{aligned}
E_{2}=\delta v\left(\bar{s} \sum_{j \in J} n_{2 j}\right. & \left.+\sum_{j \in J_{A}} n_{2 j} p_{j} c_{j}+\sum_{j \in J_{A}} n_{2 j}\left(\left(1-m_{2 j} w_{2 j} p_{j} r_{j}^{A^{\prime}}\right)+\left(m_{2 j}-1\right)\left(\bar{s}-\left(1-p_{j}\right) r_{j}^{G^{\prime}}\right)\right)\right) \\
& +\sum_{j \in J} n_{2 j} \gamma_{j}
\end{aligned}
$$

Difference:

$$
\begin{aligned}
\Delta E=E_{2}-E_{1}= & \delta v\left(\sum_{j \in J_{A}}\left(n_{2 j}-n_{1 j}\right) p_{j} c_{j}\right. \\
& +\sum_{j \in J_{A}} n_{2 j}\left(\left(1-m_{2 j} w_{2 j}\right) p_{j} r_{j}^{A^{\prime}}+\left(m_{2 j}-1\right)\left(\bar{s}-\left(1-p_{j}\right) r_{j}^{G^{\prime}}\right)\right) \\
& \left.-\sum_{j \in J_{A}} n_{1 j}\left(\left(1-m_{1 j} w_{1 j}\right) p_{j} r_{j}^{A^{\prime}}+\left(m_{1 j}-1\right)\left(\bar{s}-\left(1-p_{j}\right) r_{j}^{G^{\prime}}\right)\right)\right)+\sum_{j \in J}\left(n_{2 j}-n_{1 j}\right) \gamma_{j}
\end{aligned}
$$

We examine $\Delta E$ for two special cases, illustrated in Figure S1: Case (a) when $\Delta E$ is comparing scenarios with AFV incentives to those without, and Case (b) when $\Delta E$ is comparing scenarios with ZEV policy to scenarios without ZEV policy. We examine each in turn and identify the relevant sufficiency conditions for each from the main text.

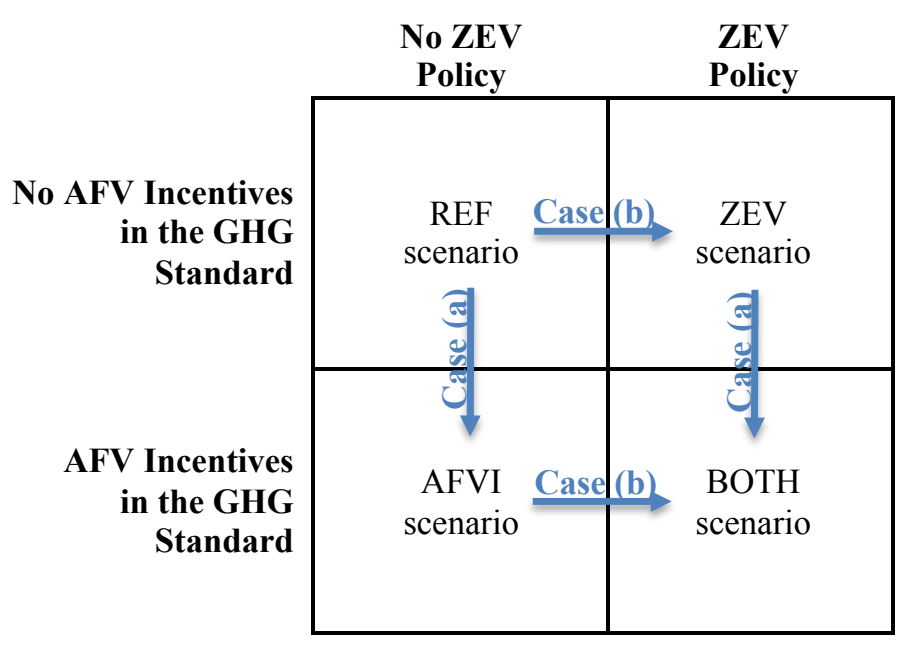

Figure S1: Illustration of policy comparison cases

\subsection{Case (a):}

When comparing a scenario with $\mathrm{AFV}$ incentives to a scenario without $\mathrm{AFV}$ incentives (e.g.: comparing the BOTH scenario to the ZEV scenario or comparing the AFVI scenario to the REF scenario in Figure S1), $m_{1 j}=w_{1 j}=1$ and $m_{2 j}=m_{j}$ and $w_{2 j}=w_{j}$, so:

$$
\Delta E=\delta v \sum_{j \in J_{A}}\left(n_{2 j}-n_{1 j}\right) p_{j} c_{j}+\delta v \sum_{j \in J_{A}} n_{2 j}\left(\left(1-m_{j} w_{j}\right) p_{j} r_{j}^{A^{\prime}}+\left(m_{j}-1\right)\left(\bar{s}-\left(1-p_{j}\right) r_{j}^{G^{\prime}}\right)\right)+\sum_{j \in J}\left(n_{2 j}-n_{1 j}\right) \gamma_{j}
$$

In this expression, assuming AFV incentives do not decrease AFV sales [Condition \#1], so that $n_{2 j} \geq n_{1 j} \forall j \in J_{\mathrm{A}}$ :

- The first term is nonnegative if the electricity production emission factors used in agency compliance calculations match those in practice $\left(c_{j}=0\right)$ or are optimistic $\left(c_{j}>0\right)$ [Condition \#4].

- The second term can be examined in cases: 
- For AFVs and years where $w_{j}=1$ and $m_{j}=1$ (such as FFVs from 2017-2025), the second term is zero.

- For AFVs and years where $w_{j}=1$ and $m_{j}>1$ (such as CNVGs from 2017-2021), the second term is positive so long as the AFV has lower operation emissions $p_{j} r_{j}^{A^{\prime}}+\left(1-p_{j}\right) r_{j}^{G^{\prime}}$ than the average vehicle in the fleet $\bar{s}$ and positive sales $n_{2 j}$ [Condition \#2].

$\circ$ For AFVs and years where $0 \leq w_{j}<1$ and $m_{j}=1$ (such as FFVs in 2012-2016 or PEVs and FCVs in 2012-2016 and 2022-2025), the second term is nonnegative.

$\circ$ For AFVs and years where $w_{j}=0$ and $m_{j}>1$ (such as PEVs and FCVs in 2017-2021), the second term is positive if the AFV has lower gasoline-related emissions $\left(1-p_{j}\right) r_{j}^{G^{\prime}}$ than the average vehicle in the fleet $\bar{s}$ [Condition $\# 2$ ].

- The last term is nonnegative if the vehicle production emissions for the AFVs are equal to or larger than the gasoline vehicles they displace [Condition \#3].

So, under fairly general conditions, emissions are higher with AFV incentives than they are without.

\subsection{Case (b):}

When comparing two scenarios with the same AFV incentives, one with ZEV policy and the other without (e.g: comparing the BOTH scenario to the AFVI scenario or comparing the ZEV scenario to the REF scenario in Figure $\mathrm{S} 1), m_{1 j}=m_{2 j}=m_{j}$ and $w_{1 j}=w_{2 j}=w_{j}$, so

$$
\begin{aligned}
\Delta E=\delta v \sum_{j \in J_{A}}\left(n_{2 j}-n_{1 j}\right) p_{j} c_{j}+\delta v \sum_{j \in J_{A}}\left(n_{2 j}-n_{1 j}\right)\left(p_{j} r_{j}^{A^{\prime}}\left(1-m_{j} w_{j}\right)+\left(m_{j}-1\right)\left(\bar{s}-\left(1-p_{j}\right) r_{j}^{G^{\prime}}\right)\right) \\
+\sum_{j \in J}\left(n_{2 j}-n_{1 j}\right) \gamma_{j}
\end{aligned}
$$

In this expression, assuming ZEV policy does not decrease AFV sales [Condition \#1], so that $n_{2 j} \geq n_{1 j} \forall j \in J_{\mathrm{A}}$ :

- The first term is nonnegative if the electricity production emission factors used in compliance calculations match those in practice $\left(c_{j}=0\right)$ or are optimistic $\left(c_{j}>0\right)$ [Condition \#4].

- The second term can be examined in cases:

$\circ \quad$ For AFVs and years where $w_{j}=1$ and $m_{j}=1$ (such as FFVs from 2017-2025), the second term is zero.

- For AFVs and years where $w_{j}=1$ and $m_{j}>1$ (such as CNVGs from 2017-2021), the second term is nonnegative so long as the AFV has lower use phase emissions $p_{j} r_{j}^{A^{\prime}}+\left(1-p_{j}\right) r_{j}^{G^{\prime}}$ than the average vehicle in the fleet $\bar{s}$ [Condition \#2].

$\circ$ For AFVs and years where $0 \leq w_{j}<1$ and $m_{j}=1$ (such as FFVs in 2012-2016 or PEVs and FCVs in 2012-2016 and 2022-2025), the second term is nonnegative so long as the AFV has positive alternative fuel emissions $p_{j} r_{j}^{A^{\prime}}$ and strictly positive when ZEV policy increases ZEV sales [Condition \#1].

$\circ$ For AFVs and years where $w_{j}=0$ and $m_{j}>1$ (such as PEVs and FCVs in 2017-2021), the second term is positive so long as the AFV has lower gasoline-related emissions $\left(1-p_{j}\right) r_{j}^{G^{\prime}}$ than the average vehicle in the fleet $\bar{s}$ and ZEV policy increases ZEV sales [Condition \#2].

- The last term is nonnegative if the vehicle production emissions for the AFV are equal to or larger than the gasoline vehicles they displace [Condition \#3].

So, under fairly general conditions, net emissions are higher with the ZEV mandate than they are without.

In particular, if there are no AFV incentives (comparing ZEV to REF in Figure S1), then $m_{1 j}=m_{2 j}=1$ and $w_{1 j}=w_{2 j}=1$, so the second term in the prior equation is zero:

$$
\Delta E=\delta v \sum_{j \in J_{A}}\left(n_{2 j}-n_{1 j}\right) p_{j} c_{j}+\sum_{j \in J}\left(n_{2 j}-n_{1 j}\right) \gamma_{j}
$$




\subsection{Summary}

Table S4 summarizes these results using the policy scenarios from Figure S1 under the conditions described above.

Table S4: Summary of findings

\begin{tabular}{|c|c|c|}
\hline $\begin{array}{c}\text { Reference } \\
\text { policy scenario }\end{array}$ & $\begin{array}{c}\text { Comparison } \\
\text { policy scenario }\end{array}$ & $\begin{array}{c}\text { Effect of } \\
\text { changing policy }\end{array}$ \\
\hline REF & ZEV & Increases net emissions by Case (b) \\
\hline REF & AFVI & Increases net emissions by Case (a) \\
\hline ZEV & BOTH & Increases net emissions by Case (a) \\
\hline AFVI & BOTH & Increases net emissions by Case (b) \\
\hline
\end{tabular}

\section{SUPPORTING EVIDENCE FOR THE SUFFICIENT CONDITIONS}

We provide supporting evidence that each of the conditions identified in the previous section and other key modeling assumptions hold in practice.

\subsection{Binding GHG Standard}

Our model makes the assumption that GHG emission standards are binding for the U.S. fleet, meaning the standards force automakers to have a lower-emitting fleet than they would have otherwise and incentivize the industry to comply, but not over-comply, with the standard.

The law requires that the GHG standard must be satisfied by each automaker. Automakers that over-comply (producing a lower-emitting fleet than their standard) earn credits that can be sold to automakers that under-comply (producing a higher-emitting fleet than their standard) as an alternative compliance mechanism. Further, automakers that over-comply in one year earn credits that can be banked for use in future years when the automaker's fleet under-complies. Our assumption is that overall, across the fleet and across time, the industry will use any credits earned and produce a fleet that complies exactly with the standard.

We summarize three pieces of evidence that the standards are binding for the U.S. fleet:

1. Credit Trading: Credits to automakers whose fleets are lower-emitting than the standard can sell those credits to other automakers as a mechanism of compliance. Leard and McConnell (2015) estimate that these credits have been traded at values between about \$36 and \$63 per credit in 2012-2013, and in 2014 the EPA estimated the value of foregone credits in a settlement at about $\$ 42$ per credit. If the standards were not binding, the credits would be expected to have no value.

2. Automaker Engagement: The stated policy intent of the CAFE and GHG standards is to reduce gasoline consumption and GHG emissions of the fleet, respectively ${ }^{6,7}$. If the standards were not binding, they would not affect gasoline consumption or GHG emissions. If the standards were not binding, the automotive industry would not have an incentive to invest in lobbying to relax the stringency of the standards, yet automakers have lobbied heavily to relax the standards, saying they are too stringent and would be difficult to meet, ${ }^{8,9}$ and automotive lobbying expenditures peaked in 2007, when the Energy Information and Security Act of 2007 (which tightened the standards) was being negotiated ${ }^{10}$.

3. Historical Fleets: Jenn et al. (2016) show that for every manufacturer except Tesla the manufacturer's 2009 fleet (before the EPA standards) would not have satisfied the 2016 EPA GHG fleet standard for cars

\footnotetext{
${ }^{6}$ Light-Duty Vehicle Greenhouse Gas Emissions Standards and Corporate Average Fuel Economy Standards; Final Rule. Federal Register 75, May 7, 2010, pp 25324-25728.

${ }^{7} 2017$ and Later Model Year Light-Duty Vehicle Greenhouse Gas Emissions and Corporate Average Fuel Economy Standards; Final Rule. Federal Register 77, October 15, 2012, pp 62623-63200.

${ }^{8}$ Boudette, Neal. "Automakers Call on E.P.A. Chief to Ease Fuel-Efficiency Standards". The New York Times. Feb 22, 2017.

https://www.nytimes.com/2017/02/22/business/energy-environment/automakers-pruitt-mileage-rules.html?_r=2

${ }^{9}$ Federal Register Light-Duty Vehicle Greenhouse Gas Emissions Standards and Corporate Average Fuel Economy Standards; Final Rule. Federal Register 75, May 7, 2010, pp 25324-25728.

${ }^{10}$ Center for Responsive Politics, OpenSecrets.org, Automotive Industry Lobbying Data, https://www.opensecrets.org/lobby/indusclient.php?id=M02\&year=2017
} 
nor light duty trucks. It is plausible that the efficiency of each automaker's fleet might have increased enough by 2016 to meet the 2016 levels even without a tightening standard, but the evidence suggests otherwise. As automotive technology develops, automakers can direct that technology to improve fuel efficiency or to improve other attributes, like performance. Klier and Linn (2012) find that consumers value an increase in power more than an increase in fuel economy, and Klier and Linn (2015) find evidence that tightening fuel economy standards have affected both the rate and direction of technology adoption, causing automakers to use technology improvement more toward efficiency and less toward horsepower and torque than they would have in a counterfactual scenario without a binding standard.

A potential critique of the binding standard assumption might note that automakers overall have over-complied with the standard in recent years. However, as noted by Leard and McConnell (2015), automakers have incentives to bank credits in early years in order to spend or trade them in later years to reduce the cost of compliance. So, this observed behavior is not inconsistent with a binding standard. While our model assumes that the industry satisfies the standard exactly in every year, banking credits in one year for use in a future year produces the same total GHG emissions per mile as meeting the standard exactly every year, except for the potential effects of banking on net GHG emissions that may occur due to annual sales volume changes over time or changes in vehicle miles traveled over time that coincide with years of over-compliance or under-compliance, but we ignore these small variations. If automakers do bank credits when incentives are high to use them when incentives are low, our estimates may be optimistic.

\subsection{Total Sales Fixed}

We assume that the changes in policy examined here can affect vehicle design or sales mix but not total vehicle sales. In practice, policies that make vehicles more expensive could reduce sales of new vehicles relative to other goods and services (such as used vehicles or public transportation). Accounting for the emissions consequences of such effects would require a model of the entire economy, since the substitute goods and services (e.g.: used cars, public transit, or expenses unrelated to transportation) all have emissions implications as well. For tractability, we ignore these effects in our main analysis and assume that the primary effect of these polices is to shift sales mix and new vehicle design.

Figure S2 shows how our results change if the alternative policy scenarios also affect total vehicle sales. The lines represent base assumptions, and the shaded regions represent the range spanned by optimistic and pessimistic assumptions (error bars). The top panel (a) shows the entire range of uncertainty, and the bottom panel (b) shows all sources of uncertainty in the model except error in agency estimates of upstream AFV emissions (e.g.: error in estimating electricity grid emissions for EVs). In Figure S2b, our key result (that fleet emissions are higher under the BOTH scenario than under the ZEV and AFVI scenarios) holds for the new vehicle fleet if the effect of both policies together does not reduce new vehicle sales by more than $1 \%$ relative to either policy alone. If the combined policies were to affect new vehicle sales significantly, it would likely also affect the used vehicle market.

Because AFVIs relax the fleet constraint, adding the policy is not likely to reduce net sales. The effect of ZEV policy on fleet sales is less clear - the policy may increase cost of compliance for a subset of the fleet, but it also reduces cost of compliance with the GHG standard for the remaining majority of the fleet, so net impact on vehicle prices and sales is less clear. 

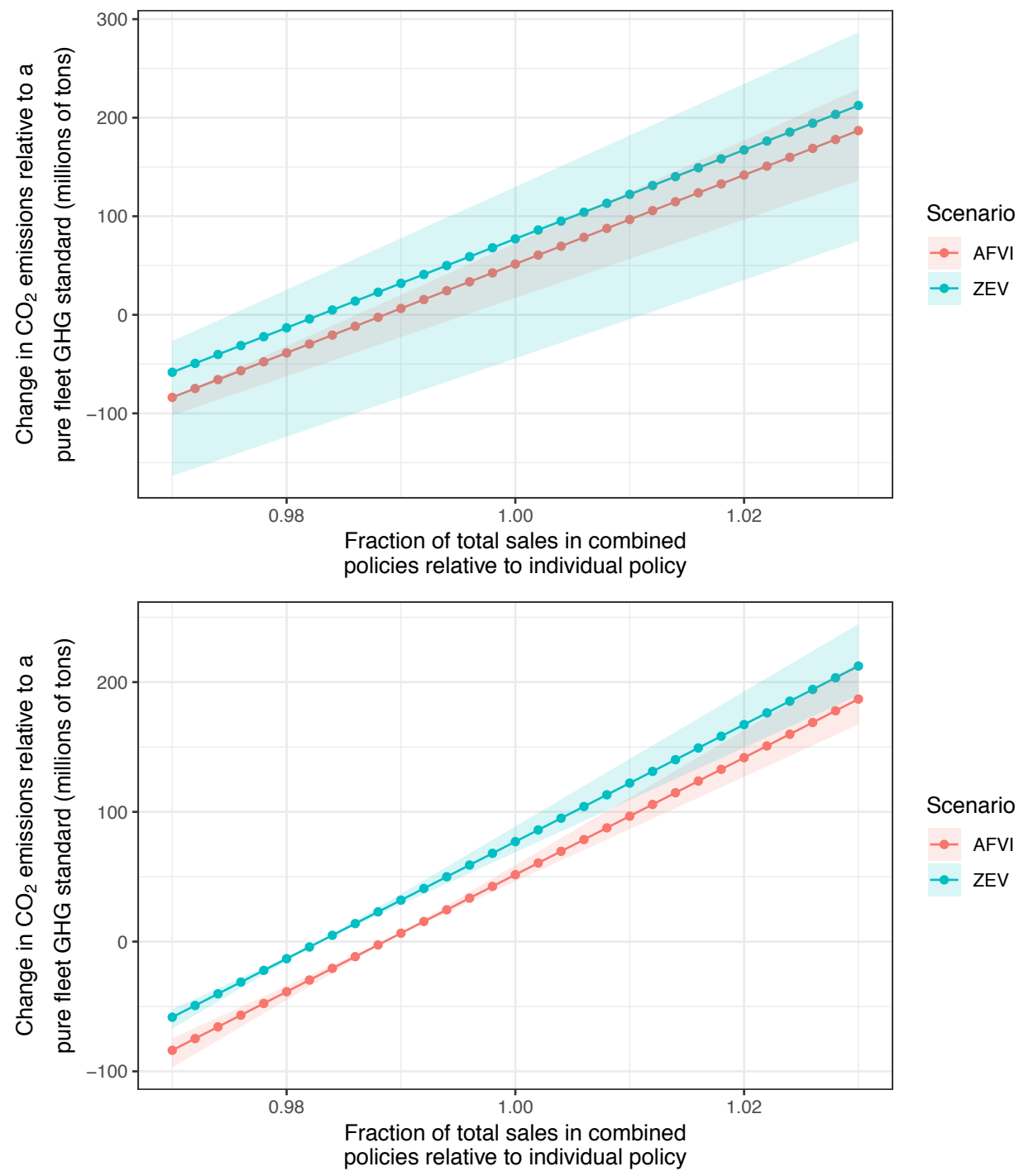

Figure S2: Sensitivity analysis for the change in $\mathrm{CO}_{2}$ emissions in the BOTH scenario relative to the ZEV and AFVI scenarios when the BOTH scenario changes total vehicle sales relative to the ZEV or AFVI scenario. The $\mathrm{x}$-axis indicates a range of assumptions about the change in total vehicle sales under the BOTH scenario relative to the ZEV or AFVI scenario. The uncertainty range is represented by the shaded areas. (a) Full range of uncertainty; (b) uncertainty from error in agency estimation of upstream AFV emissions removed.

\subsection{Incentives Increase Sales}

We assume that ZEV policy and AFV incentives each increase sales of at least some AFVs and do not decrease sales of other AFVs. It is plausible that a policy could shift sales from one type of AFV to another, increasing sales for one AFV and reducing sales of the other AFV. If any AFV sales are reduced, this condition is not strictly satisfied. However, because AFVs make up such a small share of the market, new AFV sales substitute primarily for conventional vehicle sales. We expect any effect of these policies on lowering other AFV sales to be minimal, and our simulation studies suggest the same.

It is also plausible that AFV incentives could reduce AFV sales (by making the standard easier to satisfy and making AFVs less necessary for compliance), but we ignore this possibility in our analysis. If AFV incentives were to reduce AFV sales, this would represent a different type of unintended consequence and policy failure. 


\subsection{AFV Operation Emissions}

This condition requires only that AFV operation emissions, weighted by change in sales, are lower than the fleet average. Table S5 illustrates that AFV operation emissions are lower than the fleet average in practice.

Table S5: Comparison of AFV emissions to the fleet average

\begin{tabular}{lc}
\hline Fleet Average in 2016 & $\mathbf{2 2 5} \mathrm{g} / \mathbf{m i}$ or 39.5 MPG \\
\hline Hyundai Ioniq (2017) & $25 \mathrm{kWh} / 100 \mathrm{mi}$ or $144 \mathrm{~g} / \mathrm{mi}$ \\
Chevrolet Bolt (2017) & $28 \mathrm{kWh} / 100 \mathrm{mi}$ or $160 \mathrm{~g} / \mathrm{mi}$ \\
Volkswagen e-Golf (2016) & $29 \mathrm{kWh} / 100 \mathrm{mi}$ or $166 \mathrm{~g} / \mathrm{mi}$ \\
Nissan Leaf (2016) & $30 \mathrm{kWh} / 100 \mathrm{mi}$ or $172 \mathrm{~g} / \mathrm{mi}$ \\
Chevrolet Volt (2016) & $31 \mathrm{kWh} / 100 \mathrm{mi}$ electric, $42 \mathrm{MPG}$ \\
& or $178 \mathrm{~g} / \mathrm{mi}$ electric or $212 \mathrm{~g} / \mathrm{mi} \mathrm{gas}$ \\
Tesla Model S (2016) & $38 \mathrm{kWh} / 100 \mathrm{mi}$ or $218 \mathrm{~g} / \mathrm{mi}$
\end{tabular}

\subsection{AFV Production Emissions}

This condition requires only that the sales weighted average AFV production emissions are comparable or greater than that of the vehicles they displace. Figure S3 illustrates that AFV production emissions are comparable to or higher than conventional vehicle production emissions in practice.

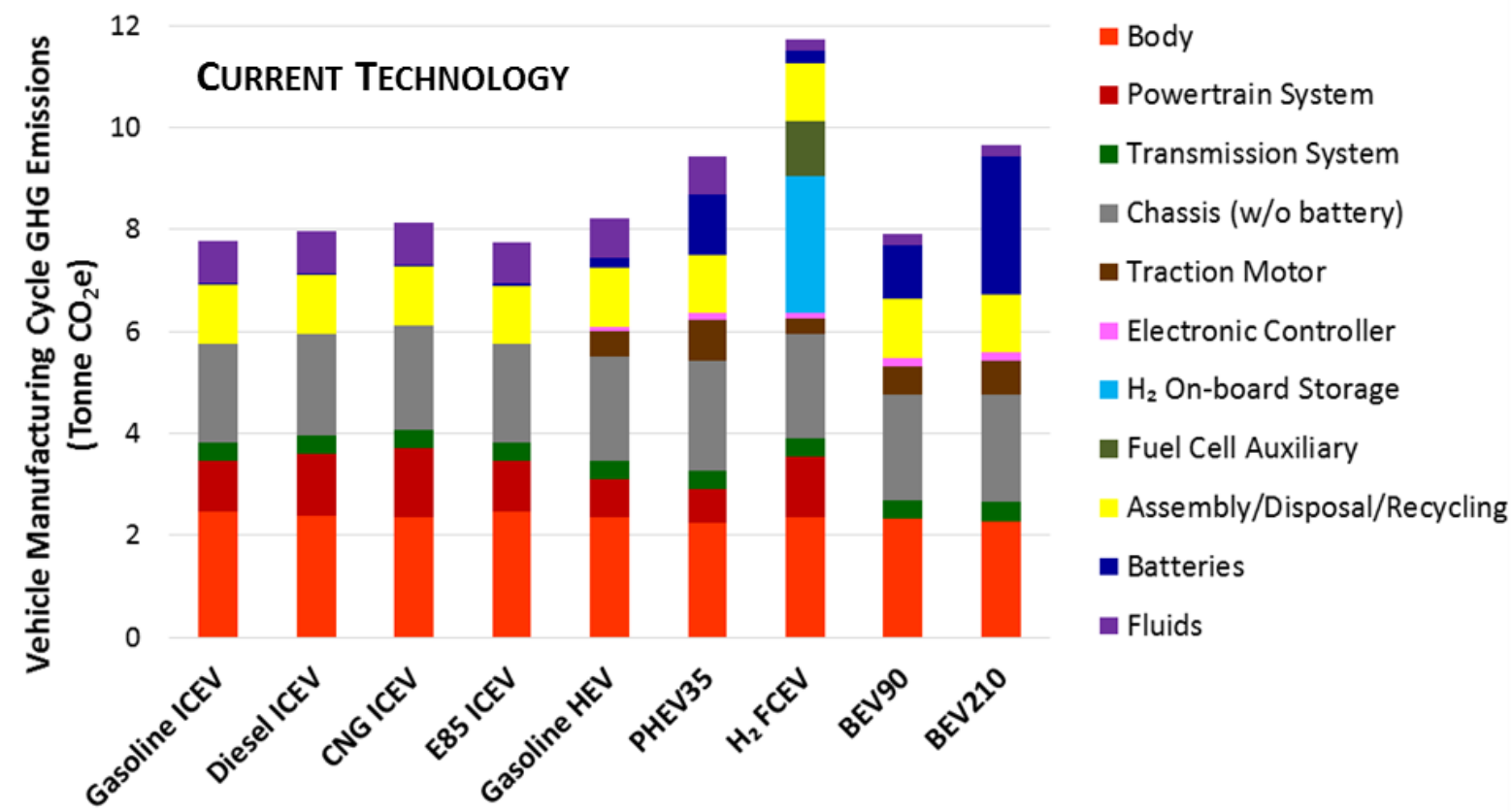

Figure S3: Vehicle cycle GHG emissions by vehicle component. Figure from Figure C.6. from Argonne National Laboratory Report ANL/ESD-16/7 "Cradle-to-Grave Lifecycle Analysis of U.S. Light-Duty Vehicle-Fuel Pathways: A Greenhouse Gas Emissions and Economic Assessment of Current (2015) and Future (2025-2030) Technologies".

\subsection{Agency Grid Emissions Estimates}

Consequential grid emissions from electric vehicle charging are uncertain, so agency estimates could be higher or lower than the true emissions triggered by electric vehicle adoption. If they are lower or equal, our condition holds. If the agency overestimates grid emissions for compliance calculations, as it does for a portion of the uncertainty range in our simulation study, this condition does not strictly hold. However, in our simulation studies (which take the current EPA grid emissions estimates for electric vehicles as given and vary the true emissions from vehicle charging across a wide range of potential emission factors in the literature) our key findings hold for all marginal 
emission factors below $1,160 \mathrm{~g} \mathrm{CO}_{2} / \mathrm{kWh}$, which is very near the extreme end of the uncertainty. Figure $\mathrm{S} 4$ shows

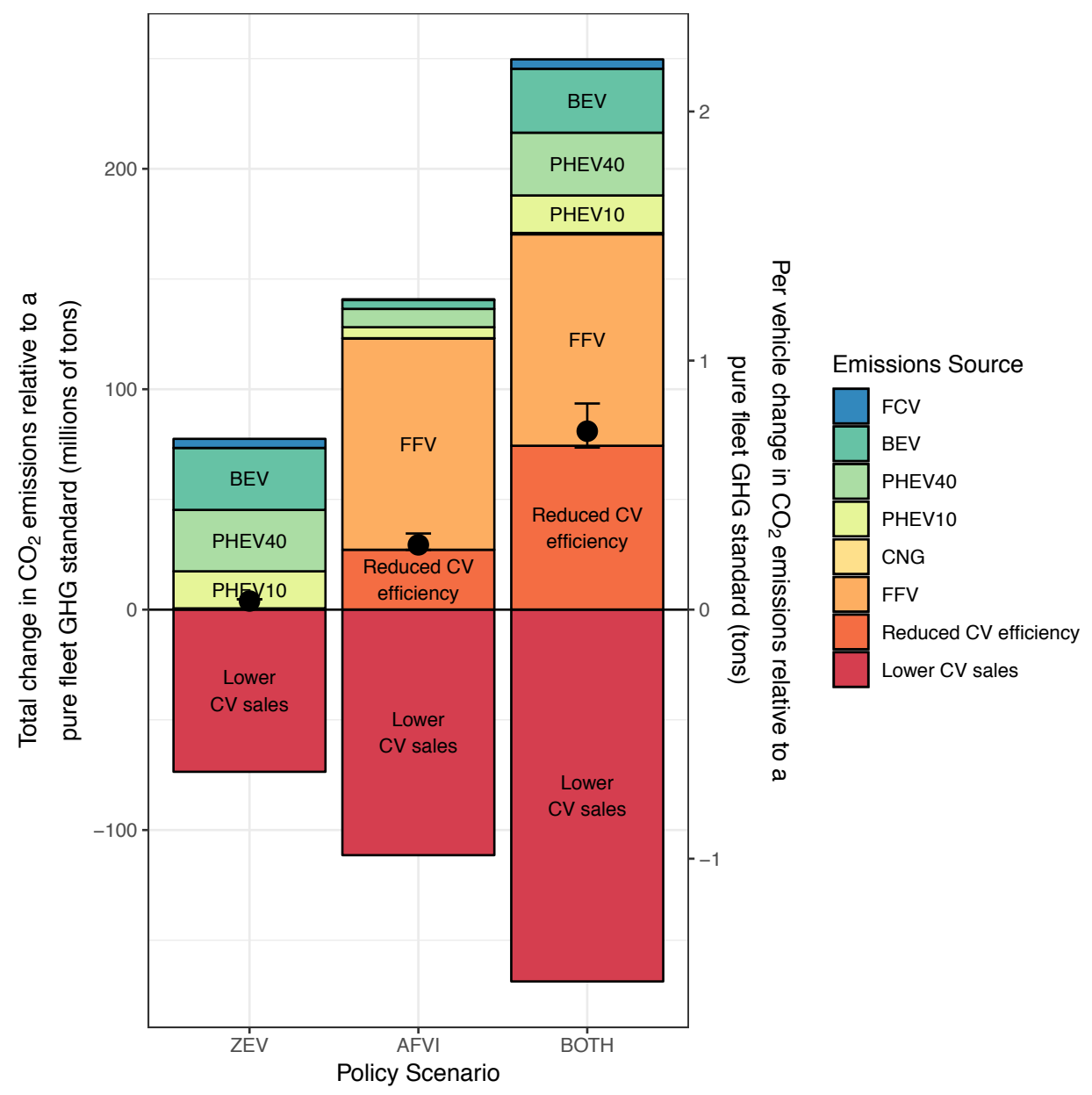

Figure S4: Total change in emissions for the fleet of model year 2012 through 2025 passenger cars relative to a baseline scenario of pure light-duty fleet GHG standards (with no AFV incentives or mandates). The figure is identical to Figure 3 in the main document with the exception that the uncertainty in EPA's estimate of the electricity grid (parameter $c$ ) is removed.

\subsection{Potential changes to the standards}

Under the Trump administration, the Environmental Protection Agency has made motions to overturn the current set of fuel economy standards and freeze them to 2020 levels ${ }^{11,12}$. We repeated our analysis, modifying parameters for both the emission rate requirements (keeping them at 2020 levels for all years proceeding it) as well as fixing the multiplier AFV incentives (rather than phasing them out) at 2020 levels. The results are consistent with the main findings of the paper, with any scenarios including AFVIs increasing in magnitude of emissions since the multipliers are kept in place. We find in the combined "BOTH" scenario, there is an emissions increase of 94 million tons of $\mathrm{CO}_{2}$, a 13 million ton increase over our main set of results in the main text.

\footnotetext{
${ }^{11} \mathrm{https} / / \mathrm{www}$.theatlantic.com/science/archive/2018/06/how-the-carmakers-trumped-themselves/562400/

${ }^{12}$ https://www.nbcnews.com/business/autos/epa-automakers-head-showdown-obama-era-mileage-rules-n872266
} 


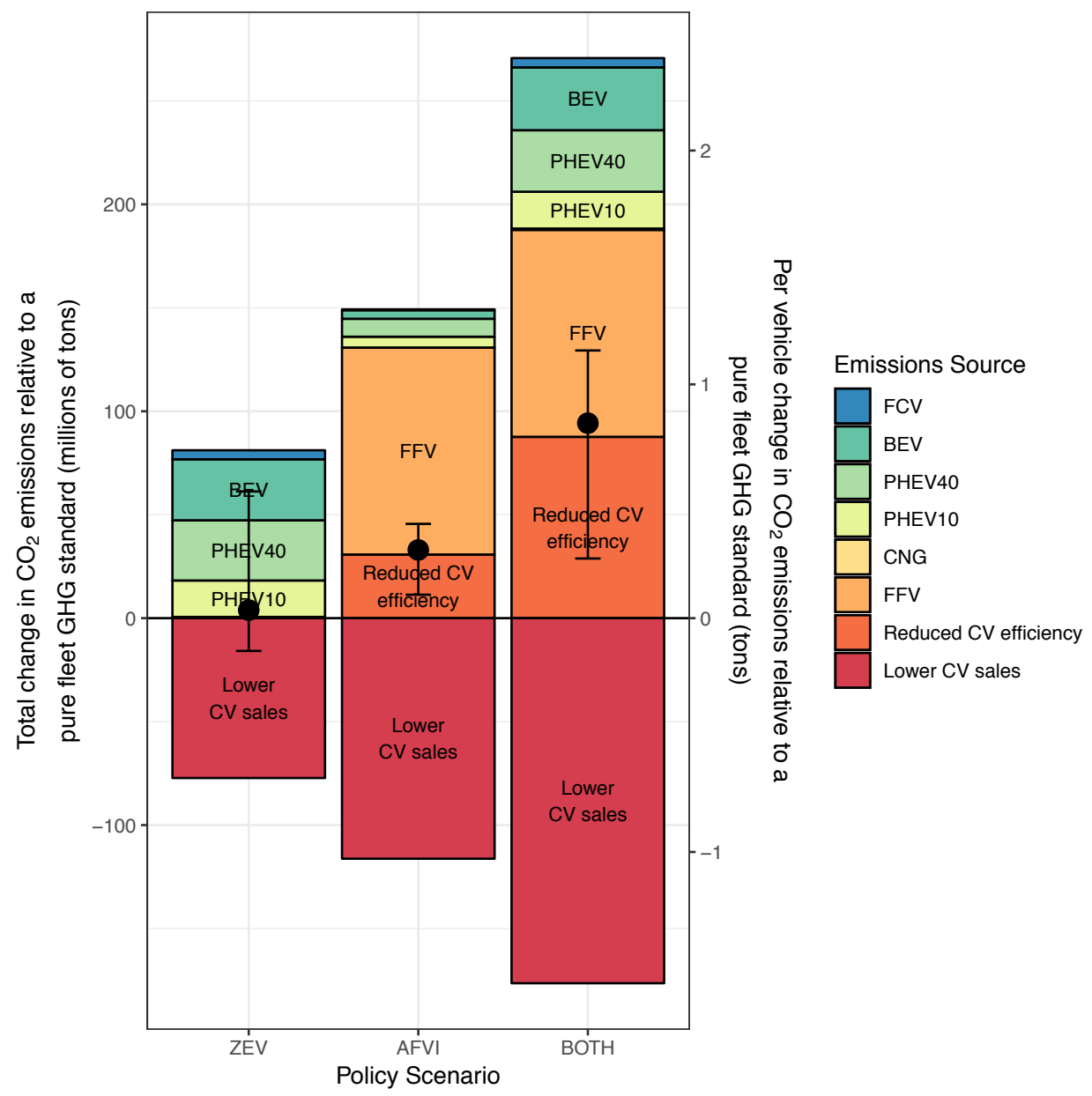

Figure S5: Total change in emissions for the fleet of model year 2012 through 2025 passenger cars relative to a baseline scenario of pure light-duty fleet GHG standards (with no AFV incentives or mandates) if the AFV incentives from 2020 are extended to 2025. 


\section{DATA}

313 In this section we describe the inputs used to estimate the emissions resulting from the sale of new vehicles from 3142012 through 2025.

\section{$315 \quad 5.1 \quad$ Vehicle attribute input tables}

316 The input attribute tables include vehicle operational inputs of alternative fuel vehicles based on representative 317 vehicle models in each technology class (Table S6), production emissions associated with construction of batteries 318 for electric vehicles (Table S7), and marginal emission rates from the power sector associated with charging electric 
Table S8). In-depth discussion on how these inputs are used in the model can be found in the Methods section of the main text.

Table S6: Summary of vehicle input attributes.13

\begin{tabular}{ccccc}
\hline $\begin{array}{c}\text { Vehicle Make } \\
\text { and Model }\end{array}$ & $\begin{array}{c}\text { Vehicle } \\
\text { Type }\end{array}$ & $\begin{array}{c}\text { Gasoline Emissions } \\
\text { Rate, } r^{G}\left[\mathrm{~g} \mathrm{CO}_{2} / \mathrm{mi}\right]\end{array}$ & $\begin{array}{c}\text { Alternative Fuel Emissions } \\
\text { Rate, } r^{\mathrm{A}}\left[\mathrm{g} \mathrm{CO}_{2} / \mathrm{mi}\right]\end{array}$ & $\begin{array}{c}\text { Proportion of Operation } \\
\text { on Alternative Fuel, } p\end{array}$ \\
\hline$\dagger$ & FFV & 221 & 221 & 0.50 \\
Nissan Leaf & BEV & $\mathrm{n} / \mathrm{a}$ & 144 & 1 \\
Toyota Prius & PHEV10 & 127 & 143 & 0.29 \\
Chevrolet Volt & PHEV40 & 177 & 171 & 0.66 \\
Honda Civic & $\mathrm{CNG}$ & $\mathrm{n} / \mathrm{a}$ & 345 & 1 \\
$\dagger \dagger$ & $\mathrm{FCV}$ & $\mathrm{n} / \mathrm{a}$ & 171 & 1 \\
$\dagger-$ - Average emissions from historical sales weighted emissions for all FFVs sold from 2002 through 2011. & \\
$\dagger \dagger$ - Emissions from fuel utilization stage of fuel cell usage as measured in Granovskii et al. (2006), Table 8. &
\end{tabular}

Table S7: Life cycle $\mathrm{CO}_{2}$ emissions from EV lithium-ion batteries. We examine the full range of values implied by these estimates in our sensitivity analysis (from $39 \mathrm{kgCO}_{2} / \mathrm{kWh}$ to $278 \mathrm{kgCO}_{2} / \mathrm{kWh}$ ).

\begin{tabular}{lcccc}
\hline Source & Vehicle Type & $\mathrm{kWh} / \mathrm{kg}$ battery & $\mathrm{kg} \mathrm{CO}_{2} / \mathrm{kg}$ battery & Implied $\mathrm{kg} \mathrm{CO}_{2} / \mathrm{kWh}$ \\
\hline Notter et al. (2010) & $\mathrm{BEV}$ & 0.11 & 6 & 55 \\
Majeau-Bettez et al. (2011) & PHEV & 0.11 & 22 & 200 \\
Majeau-Bettez et al. (2011) & PHEV & 0.09 & 22 & 244 \\
Zackrisson et al. (2010) & PHEV & 0.09 & 25 & 278 \\
Hart et al. (2013) & PHEV & 0.08 & 5 & 63 \\
Hart et al. (2013) & BEV & 0.1 & 16 & 160 \\
Dunn et al. (2012) & PHEV & 0.11 & 5.1 & 46 \\
Dunn et al. (2012) & BEV & 0.13 & 5.1 & 39
\end{tabular}

13 The data were obtained using unadjusted fuel efficiency figures from the 2015 Fuel Economy Datafile from the Office of Transportation \& Air Quality from the US EPA at http://www.fueleconomy.gov/feg/download.shtml, conversion to emission rates from $\mathrm{kWh} / 100$ miles by EPA conversion factors at http://www.epa.gov/cleanenergy/energy-resources/refs.html 
Table S8: Marginal emission rates and upstream emissions ${ }^{14}$ for sensitivity analysis.

\begin{tabular}{|c|c|c|c|c|c|}
\hline $\begin{array}{l}\text { Vehicle } \\
\text { Technology }\end{array}$ & $\begin{array}{c}\text { Efficiency } \\
(\mathrm{kWh} / 100 \mathrm{mi})\end{array}$ & $\begin{array}{l}\text { Base marginal } \\
\text { emissions factor } \\
\text { plus upstream } \\
\text { emissions } \\
\left(\mathrm{g} \mathrm{CO}_{2} / \mathrm{kWh}\right)\end{array}$ & $\begin{array}{l}\text { Low marginal } \\
\text { emissions factor } \\
\text { plus upstream } \\
\text { emissions } \\
\left(\mathrm{g} \mathrm{CO}_{2} / \mathrm{kWh}\right)\end{array}$ & $\begin{array}{l}\text { High marginal } \\
\text { emissions factor } \\
\text { plus upstream } \\
\text { emissions } \\
\left(\mathrm{g} \mathrm{CO}_{2} / \mathrm{kWh}\right)\end{array}$ & $\begin{array}{c}c_{i} \\
\left(\mathrm{~g} \mathrm{CO}_{2} / \mathrm{mi}\right) \\
{[\text { low, mid, high] }}\end{array}$ \\
\hline BEV & $\begin{array}{c}20.7357 \\
\text { (Nissan Leaf) }\end{array}$ & $\begin{array}{c}615 \\
\text { (Nationwide }\end{array}$ & & & {$[-57.2,0,146.8]$} \\
\hline PHEV10 & $\begin{array}{c}20.2342 \\
\text { (Toyota Prius PHEV) }\end{array}$ & $\begin{array}{l}\text { average } \\
\text { electricity }\end{array}$ & $\begin{array}{c}340 \\
\text { (WECC at } 7 \\
\text { AM) }\end{array}$ & $\begin{array}{l}\text { (MRO, at } 2 \\
\text { AM) }\end{array}$ & {$[-55.8,0,143.3]$} \\
\hline PHEV40 & $\begin{array}{c}24.1 \\
\text { (Chevrolet Volt) }\end{array}$ & $\begin{array}{l}\text { upstream GHG } \\
\text { emissions rate) }\end{array}$ & & & {$[-66.5,0,170.6]$} \\
\hline
\end{tabular}

\subsection{Sales Projections}

For our simulation studies, we adopt sales projections from the Energy Information Administration's Annual Energy Outlook and from the California Air Resources Board, and when the projections group technologies, we make assumptions where necessary to allocate those sales projections across the specific vehicle technologies we model. In all cases total fleet sales is held constant, and any changes to AFV sales are offset by conventional vehicle sales. Table S9 - Table S12 detail the projections across the four cases. We employ the use of several sets in the mathematical notation below to categorize vehicle technologies:

- $J=\left\{\mathrm{CV}, \mathrm{PHEV}, \mathrm{PHEV}_{10}, \mathrm{PHEV}_{40}, \mathrm{BEV}, \mathrm{FCV}, \mathrm{FFV}, \mathrm{CNG}\right\}$

- $J_{A}=\left\{\mathrm{PHEV}_{10}, \mathrm{PHEV}_{40}, \mathrm{BEV}, \mathrm{FCV}, \mathrm{FFV}, \mathrm{CNG}\right\}$

- $J_{A}^{\mathrm{CARB}}=\{\mathrm{PHEV}, \mathrm{BEV}, \mathrm{FCV}\}$

- $J_{N}^{C A R B}=\{\mathrm{FFV}, \mathrm{CNG}\}$

- $J_{C}=\{\mathrm{CV}\}$

- $J_{A}^{\mathrm{ZEV}}=\left\{\mathrm{PHEV}_{10}, \mathrm{PHEV}_{40}, \mathrm{BEV}, \mathrm{FCV}\right\}$

- $J_{A}^{\mathrm{EV}}=\left\{\mathrm{PHEV}_{10}, \mathrm{PHEV}_{40}, \mathrm{BEV}\right\}$

Due to the uncertain nature of future AFV sales, we investigate four different projections of AFV adoption:

1. Base Case: As a base case, our results use vehicle sales projections modified from the Energy Information Agency's 2015 Annual Energy Outlook (AEO) projections through 2025. Vehicle technologies from the AEO projection include CVs, FFVs, BEVs, PHEVs, CNGVs, and FCVs. The AEO sales projections are made assuming the presence of CAFE/GHG and ZEV policy, and they attribute a portion of projected sales to ZEV policy. For our ZEV scenarios we adopt the AEO projections. For our non-ZEV scenarios, the assumed sales volume $n_{j}$ for each AFV model $j$ is modified from the original sales projection $n_{j 0}$ (with ZEV) to remove the sales attributed to ZEV policy $n_{\text {ZEV }}$. The AEO provides an overall estimate of $n_{\text {ZEV }}$, but it does not provide a breakdown for each AFV type, so we proportionally allocate the projections among all vehicle technologies:

\footnotetext{
${ }^{14}$ Marginal emission rates were obtained from the Center for Climate and Energy Decision Making "Marginal Emissions Factors Repository" (MEFR, https://cedmcenter.org/tools-for-cedm/marginal-emissions-factorsrepository/). For sensitivity, the lowest observed hourly emissions factor was used for the low and the highest observed marginal emissions factor was used for the high emissions scenario. The mean marginal emissions factor is the nationwide generation-weighted average. Upstream emissions were calculated by taking the proportion of marginal emissions coming from coal and natural gas (also from MEFR). Each proportion of marginal emission rates coming from coal and natural gas are multiplied by 1 plus the ratio of upstream emissions $(1.9 \mathrm{~g} / \mathrm{MJ}$ coal, 7.22 $\mathrm{g} / \mathrm{MJ}$ natural gas) and direct combustion emissions (91 g/MJ coal, $50 \mathrm{~g} / \mathrm{MJ}$ natural gas) for coal and natural gas, respectively, from Table 1 in DeVynne, et al. (2016) and summed to obtain the final emissions rate.
} 


$$
n_{j}=n_{j 0} \frac{\sum_{j \in J_{\mathrm{A}}} n_{j 0}-n_{\mathrm{ZEV}}}{\sum_{j \in J_{\mathrm{A}}} n_{j 0}}
$$

2. CARB/AEO Case: In this case California Air Resources Board (CARB) projections (from their light-duty vehicle 2050 scenario vehicle market data) are supplemented with AEO data, using CARB projections overall distributed using AEO-calculated attribution of ZEV technologies (designated with the S2 superscript). For the ZEV scenarios (designated with the $\mathrm{Z}$ superscript), the technologies included in the CARB projection are BEV, FCV, and PHEV. The PHEV sales are modified as follows:

$$
s_{P H E V 10}^{\mathrm{S} 2 . \mathrm{Z}}=\left(\frac{s_{P H E V 10}^{\mathrm{AEO}}}{s_{P H E V 10}^{\mathrm{AEO}}+s_{P H E V ~ 40}^{\mathrm{AEO}}}\right) s_{P H E V}^{\mathrm{CARB}} \text { and } s_{P H E V 40}^{\mathrm{S} 2 . \mathrm{Z}}=\left(\frac{s_{P H E V 40}^{\mathrm{AEO}}}{s_{P H E V 10}^{\mathrm{AEO}}+s_{P H E V ~ 40}^{\mathrm{AEO}}}\right) s_{P H E V}^{\mathrm{CARB}}
$$

where $s_{P H E V}^{\mathrm{CARB}}$ is the CARB projection of PHEV sales; $s_{P H E V 10}^{\mathrm{AEO}}$ and $s_{P H E V ~}^{\mathrm{AEO}}$ are the AEO projections of PHEV10 and PHEV40 sales, respectively; and $s_{P H E V 10}^{\mathrm{S2Z}}$ and $s_{P H E V 40}^{\mathrm{S} 2 . \mathrm{Z}}$ are the projections of PHEV10 and PHEV40 sales, respectively, used in the scenario. For the set of other $j$ technologies not specified in the CARB data:

where $s_{j}^{\mathrm{AEO}}$ is the sales projection of vehicle type $j$ in AEO projections and $s_{j}^{\mathrm{CARB}}$ is the sales projection of vehicle type $j$ in CARB projections. Lastly, for conventional vehicles: $s_{C V}^{\mathrm{S} 2 . \mathrm{Z}}=\sum_{j \in J} s_{j}^{\mathrm{CARB}}-\sum_{j \in J_{A}} s_{j}^{\mathrm{S} 2 . \mathrm{Z}}$

For the non-ZEV scenarios (denoted as the NZ superscript), we use the sales determined from the AEO scenario and scale the sales to match the CARB totals:

$$
s_{j}^{\mathrm{S} 2 . \mathrm{NZ}}=\left(\frac{s_{j}^{\mathrm{S} 1 . \mathrm{NZ}}}{\sum_{j \in J} s_{j}^{\mathrm{AEO}}}\right) \sum_{j \in J} s_{j}^{\mathrm{CARB}}, \forall j \in J
$$

3. AEO Historical ZEV Case: In this case the AEO 2015 projections are modified to meet ZEV requirements, using historical AFV sales to attribute ZEV sales to AFV types. For this case the ZEV scenarios are identical to the base case, and for the non-ZEV scenarios we take the sales calculated in the ZEV scenario above $\left(s^{\mathrm{ZEV}}\right)$ and scale to the observed historical proportion of the technology (for PHEVs and BEVs, other technology sales stay the same):

$$
s_{j}^{\mathrm{S} 3 . \mathrm{NZ}}=s_{j}^{\mathrm{S} 3 . \mathrm{Z}}\left(\frac{s_{j}^{\mathrm{NZS}}}{s_{j}^{\mathrm{ZS}}+s_{j}^{\mathrm{NZS}}}\right), \forall j \in J_{A}^{\mathrm{E} V}
$$

where $s_{j}^{\text {NZS }}$ is the average per capita sale of ZEVs in all states without ZEV mandates in the years 2011 2011 through 2015.

4. CARB/AEO Historical ZEV Case: In this case the CARB projections are supplemented with AEO data, using historical sales to attribute ZEV sales to particular AFVs. The sales are taken directly from CARB's 
projections through 2050 and combined with the AEO 2015 and historical sales of AFVs as described below. For the ZEV scenarios, the technologies included in the CARB projection are BEV, FCV, and PHEV. We leave the BEV and FCV sales as specified and distribute the PHEV sales as follows:

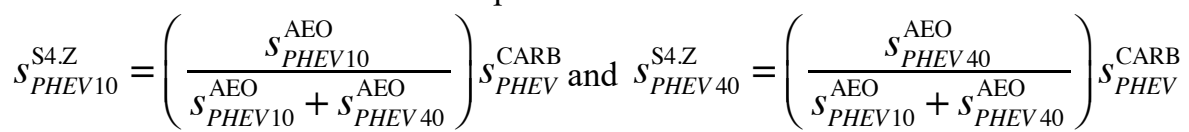

For the set of other $j$ technologies not specified in the CARB data:

$$
\begin{array}{r}
s_{j}^{\mathrm{S} 2 . \mathrm{Z}}=\left(\frac{s_{j}^{\mathrm{AEO}}}{\sum_{j \in J} s_{j}^{\mathrm{AEO}}}\right) \sum_{j \in J} s_{j}^{\mathrm{CARB}}, \forall j \in J_{N}^{\mathrm{CARB}} \\
\text { Lastly, for ICVs: } s_{C V}^{\mathrm{S} 4 . \mathrm{Z}}=\sum_{j \in J} s_{j}^{\mathrm{CARB}}-\sum_{j \in J_{A}} s_{j}^{\mathrm{S} 4 . \mathrm{Z}}
\end{array}
$$

For the non-ZEV scenarios, we take the sales calculated in the ZEV scenario above $\left(s^{Z E V}\right)$ and scale to the observed historical proportion of the technology (for PHEVs and BEVs, other technology sales stay the same):

$$
s_{j}^{\mathrm{S} 4 . \mathrm{NZ}}=s_{j}^{\mathrm{S} 4 . \mathrm{Z}}\left(\frac{s_{j}^{\mathrm{NZS}}}{s_{j}^{\mathrm{ZS}}+s_{j}^{\mathrm{NZS}}}\right), \forall j \in J_{A}^{\mathrm{EV}}
$$

For ICVs: $s_{C V}^{\mathrm{S} 4 . \mathrm{NZ}}=\sum_{j \in J} s_{j}^{\mathrm{CARB}}-\sum_{j \in J_{A}} s_{j}^{\mathrm{S} 4 . \mathrm{NZ}}$

The sales projections for BEVs, FCVs, and PHEVs can be found in Figure S6 for each of the scenarios with and without the ZEV mandate. 


\begin{tabular}{|c|c|c|c|c|c|c|c|c|c|c|c|c|}
\hline \multirow[t]{2}{*}{ Scenario } & \multirow[t]{2}{*}{ Policies } & \multirow[t]{2}{*}{ Sales } & \multirow{2}{*}{$\begin{array}{l}\text { Sales of BEVs, PHEVs, } \\
\text { and FCEVs }\end{array}$} & \multirow{2}{*}{$\begin{array}{l}\text { Sales of FFVs and } \\
\text { CNGVs }\end{array}$} & \multicolumn{8}{|c|}{ (thousands of sales) } \\
\hline & & & & & BEV & PHEV $_{10}$ & PHEV $_{40}$ & FCV & FFV & CNGV & $\mathbf{C V}$ & Total \\
\hline BOTH & $\begin{array}{l}\text { REF + } \\
\text { ZEV + } \\
\text { AFVI }\end{array}$ & $n_{\text {ВОтн }}$ & $\begin{array}{l}n_{\mathrm{BOTH}}=n_{\mathrm{AEO}}: \\
\text { AEO projections reflect } \\
\text { the projected policy } \\
\text { context (both policies) }\end{array}$ & $\begin{array}{l}n_{\mathrm{BOTH}}=n_{\mathrm{AEO}}: \\
\text { AEO projections } \\
\text { reflect the projected } \\
\text { policy context (both } \\
\text { policies) }\end{array}$ & 771 & 546 & 869 & 127 & 4,840 & 49 & 105,798 & 113,000 \\
\hline$\overline{Z E V}$ & $\begin{array}{l}\text { REF + } \\
\text { ZEV }\end{array}$ & $n_{\mathrm{ZEV}}$ & $\begin{array}{l}n_{\mathrm{ZEV}}=n_{\mathrm{AEO}}: \\
\text { We assume the } \mathrm{ZEV} \\
\text { mandate is a stronger } \\
\text { driver than the AFV } \\
\text { incentives and AFV } \\
\text { incentives do not increase } \\
\text { sales beyond the ZEV } \\
\text { mandate, so removing } \\
\text { AFV incentives without } \\
\text { removing the } \mathrm{ZEV} \\
\text { mandate does not reduce } \\
\text { AFV sales }\end{array}$ & $\begin{array}{l}n_{\mathrm{ZEV}}=n_{\mathrm{REF}}: \\
\text { No sales of these } \\
\text { vehicles are } \\
\text { attributed to } \mathrm{ZEV} \\
\text { policy, so this case } \\
\text { is identical to the } \\
\text { reference case for } \\
\text { these vehicles }\end{array}$ & 771 & 546 & 869 & 127 & $\begin{array}{l}0 \text { to } \\
4,840\end{array}$ & 49 & $\begin{array}{l}105,798 \\
\text { to } \\
110,638\end{array}$ & 113,000 \\
\hline AFVI & $\begin{array}{l}\text { REF + } \\
\text { AFVI }\end{array}$ & $n_{\mathrm{AFVI}}$ & $\begin{array}{l}n_{\mathrm{AFVI}}=n_{\mathrm{AEO}}- \\
n_{\mathrm{ATRBZEV}}: \\
\text { AEO projections minus } \\
\text { AFV sales attributed to } \\
\text { ZEV by AEO }\end{array}$ & $\begin{array}{l}n_{\mathrm{AFVI}}=n_{\mathrm{AEO}}: \\
\text { No sales of these } \\
\text { vehicles are } \\
\text { attributed to ZEV } \\
\text { policy }\end{array}$ & 172 & 243 & 383 & 20 & 4,840 & 34 & 107,308 & 113,000 \\
\hline $\begin{array}{l}\text { REF } \\
\text { (range of } \\
\text { assumpti } \\
\text { ons } \\
\text { shown } \\
\text { for AFV } \\
\text { sales } \\
\text { induced } \\
\text { by AFV } \\
\text { incentive } \\
\text { s) }\end{array}$ & $\begin{array}{l}\text { Pure } \\
\text { fleet } \\
\text { GHG } \\
\text { standard } \\
\text { s alone }\end{array}$ & $n_{\mathrm{REF}}$ & $\begin{array}{l}0 \leq n_{\mathrm{REF}} \leq n_{\mathrm{AFVI}}: \\
\mathrm{AFV} \text { sales unknown in } \\
\text { the absence of ZEV } \\
\text { mandate and AFV } \\
\text { incentives. Adopt } n_{\mathrm{REF}}= \\
\frac{n_{\mathrm{AFVI}}}{2} \text { as a base case and } \\
\text { examine full range from } \\
n_{\mathrm{REF}}=0 \text { to } n_{\mathrm{REF}}=n_{\mathrm{AFVI}} \\
\text { in sensitivity analysis. }\end{array}$ & $\begin{array}{l}0 \leq n_{\mathrm{REF}} \leq n_{\mathrm{AFVI}}: \\
\text { AFV sales unknown } \\
\text { in the absence of } \\
\text { ZEV mandate and } \\
\text { AFV incentives. } \\
\text { Adopt } n_{\mathrm{REF}}=\frac{n_{\mathrm{AFVI}}}{2} \\
\text { as a base case and } \\
\text { examine full range } \\
\text { from } n_{\mathrm{REF}}=0 \text { to } \\
n_{\mathrm{REF}}=n_{\mathrm{AFVI}} \text { in } \\
\text { sensitivity analysis. }\end{array}$ & $\begin{array}{l}0 \text { to } \\
172\end{array}$ & 0 to 243 & 0 to 383 & $\begin{array}{l}0 \text { to } \\
20\end{array}$ & $\begin{array}{l}0 \text { to } \\
4,840\end{array}$ & 0 to 34 & $\begin{array}{l}107,308 \\
\text { to } \\
113,000\end{array}$ & 113,000 \\
\hline
\end{tabular}

Table S9: Base case AFV sales volume assumptions and rationale for four policy scenarios 
Table S10: AEO with historic ZEV AFV sales volume assumptions and rationale for four policy scenarios

\begin{tabular}{|c|c|c|c|c|c|c|c|c|c|c|c|c|}
\hline \multirow[t]{2}{*}{ Scenario } & \multirow[t]{2}{*}{ Policies } & \multirow[t]{2}{*}{ Sales } & \multirow{2}{*}{$\begin{array}{l}\text { Sales of BEVs, } \\
\text { PHEVs, and FCEVs }\end{array}$} & \multirow{2}{*}{$\begin{array}{l}\text { Sales of FFVs and } \\
\text { CNGVs }\end{array}$} & \multicolumn{8}{|c|}{ (thousands of sales) } \\
\hline & & & & & BEV & PHEV 10 & PHEV $_{40}$ & FCV & FFV & CNGV & $\mathrm{CV}$ & Total \\
\hline BOTH & $\begin{array}{l}\mathrm{REF}+ \\
\mathrm{ZEV}+ \\
\mathrm{AFVI}\end{array}$ & $n_{\text {Вотн }}$ & $\begin{array}{l}n_{\mathrm{BOTH}}=n_{\mathrm{AEO}}: \\
\text { AEO projections reflect } \\
\text { the projected policy } \\
\text { context (both policies) }\end{array}$ & $\begin{array}{l}n_{\mathrm{BOTH}}=n_{\mathrm{AEO}}: \\
\text { AEO projections } \\
\text { reflect the projected } \\
\text { policy context (both } \\
\text { policies) }\end{array}$ & 771 & 546 & 869 & 127 & 4,840 & 49 & 105,798 & 113,000 \\
\hline ZEV & $\begin{array}{l}\mathrm{REF}+ \\
\mathrm{ZEV}\end{array}$ & $n_{\mathrm{ZEV}}$ & $\begin{array}{l}n_{\mathrm{ZEV}}=n_{\mathrm{AEO}}: \\
\text { We assume the ZEV } \\
\text { mandate is a stronger } \\
\text { driver than the AFV } \\
\text { incentives and AFV } \\
\text { incentives do not } \\
\text { increase sales beyond } \\
\text { the ZEV mandate, so } \\
\text { removing AFV } \\
\text { incentives without } \\
\text { removing the ZEV } \\
\text { mandate does not } \\
\text { reduce AFV sales }\end{array}$ & $\begin{array}{l}n_{\mathrm{ZEV}}=n_{\mathrm{REF}}: \\
\text { No sales of these } \\
\text { vehicles are } \\
\text { attributed to } \mathrm{ZEV} \\
\text { policy, so this case is } \\
\text { identical to the } \\
\text { reference case for } \\
\text { these vehicles }\end{array}$ & 771 & 546 & 869 & 127 & $\begin{array}{l}0 \text { to } \\
4,840\end{array}$ & 49 & $\begin{array}{l}105,798 \\
\text { to } \\
110,638\end{array}$ & 113,000 \\
\hline AFVI & $\begin{array}{l}\text { REF + } \\
\text { AFVI }\end{array}$ & $n_{\mathrm{AFVI}}$ & $\begin{array}{l}n_{\text {AFVI }}=n_{\text {AEO }}- \\
n_{\text {ATRBZEV }}: \\
\text { AEO projections minus } \\
\text { AFV sales attributed to } \\
\text { ZEV by AEO }\end{array}$ & $\begin{array}{l}n_{\mathrm{AFVI}}=n_{\mathrm{AEO}}: \\
\text { No sales of these } \\
\text { vehicles are } \\
\text { attributed to } \mathrm{ZEV} \\
\text { policy }\end{array}$ & 566 & 257 & 409 & 127 & 4,840 & 49 & 106,752 & 113,000 \\
\hline $\begin{array}{l}\text { REF } \\
\text { (range of } \\
\text { assumpti } \\
\text { ons } \\
\text { shown } \\
\text { for AFV } \\
\text { sales } \\
\text { induced } \\
\text { by AFV } \\
\text { incentive } \\
\text { s) }\end{array}$ & $\begin{array}{l}\text { Pure } \\
\text { fleet } \\
\text { GHG } \\
\text { standard } \\
\text { s alone }\end{array}$ & $n_{\mathrm{REF}}$ & $\begin{array}{l}0 \leq n_{\mathrm{REF}} \leq n_{\mathrm{AFVI}}: \\
\mathrm{AFV} \text { sales unknown in } \\
\text { the absence of } \mathrm{ZEV} \\
\text { mandate and AFV } \\
\text { incentives. Adopt } \\
n_{\mathrm{REF}}=\frac{n_{\mathrm{AFVI}}}{2} \text { as a base } \\
\text { case and examine full } \\
\text { range from } n_{\mathrm{REF}}=0 \text { to } \\
n_{\mathrm{REF}}=n_{\mathrm{AFVI}} \text { in } \\
\text { sensitivity analysis. }\end{array}$ & $\begin{array}{l}0 \leq n_{\mathrm{REF}} \leq n_{\mathrm{AFVI}}: \\
\mathrm{AFV} \text { sales unknown } \\
\text { in the absence of } \\
\mathrm{ZEV} \text { mandate and } \\
\text { AFV incentives. } \\
\text { Adopt } n_{\mathrm{REF}}=\frac{n_{\mathrm{AFVI}}}{2} \\
\text { as a base case and } \\
\text { examine full range } \\
\text { from } n_{\mathrm{REF}}=0 \text { to } \\
n_{\mathrm{REF}}=n_{\mathrm{AFVI}} \text { in } \\
\text { sensitivity analysis. }\end{array}$ & $\begin{array}{l}0 \text { to } \\
566\end{array}$ & 0 to 257 & 0 to 409 & $\begin{array}{l}0 \text { to } \\
127\end{array}$ & $\begin{array}{l}0 \text { to } \\
4,840\end{array}$ & 0 to 49 & $\begin{array}{l}106,752 \\
\text { to } \\
113,000\end{array}$ & 113,000 \\
\hline
\end{tabular}


Table S11: CARB/AEO AFV sales volume assumptions and rationale for four policy scenarios

\begin{tabular}{|c|c|c|c|c|c|c|c|c|c|c|c|c|}
\hline \multirow[t]{2}{*}{ Scenario } & \multirow[t]{2}{*}{ Policies } & \multirow[t]{2}{*}{ Sales } & \multirow{2}{*}{$\begin{array}{l}\text { Sales of BEVs, } \\
\text { PHEVs, and FCEVs }\end{array}$} & \multirow{2}{*}{$\begin{array}{l}\text { Sales of FFVs and } \\
\text { CNGVs }\end{array}$} & \multicolumn{8}{|c|}{ (thousands of sales) } \\
\hline & & & & & BEV & PHEV 10 & PHEV $_{40}$ & FCV & FFV & CNGV & $\mathbf{C V}$ & Total \\
\hline BOTH & $\begin{array}{l}\mathrm{REF}+ \\
\mathrm{ZEV}+ \\
\mathrm{AFVI}\end{array}$ & $n_{\mathrm{BOTH}}$ & $\begin{array}{l}n_{\mathrm{BOTH}}=n_{\mathrm{CARB}}: \\
\text { CARB projections } \\
\text { reflect the projected } \\
\text { policy context (both } \\
\text { policies) }\end{array}$ & $\begin{array}{l}n_{\mathrm{BOTH}}=n_{\mathrm{CARB}}: \\
\text { CARB projections } \\
\text { reflect the projected } \\
\text { policy context (both } \\
\text { policies) }\end{array}$ & 1,440 & 1,580 & 2,530 & 1,540 & 9,560 & 98 & 206,252 & 223,000 \\
\hline ZEV & $\begin{array}{l}\mathrm{REF}+ \\
\mathrm{ZEV}\end{array}$ & $n_{\mathrm{ZEV}}$ & $\begin{array}{l}n_{\mathrm{ZEV}}=n_{\mathrm{CARB}}: \\
\text { We assume the ZEV } \\
\text { mandate is a stronger } \\
\text { driver than the AFV } \\
\text { incentives and AFV } \\
\text { incentives do not } \\
\text { increase sales beyond } \\
\text { the ZEV mandate, so } \\
\text { removing AFV } \\
\text { incentives without } \\
\text { removing the ZEV } \\
\text { mandate does not } \\
\text { reduce AFV sales }\end{array}$ & $\begin{array}{l}n_{\mathrm{ZEV}}=n_{\mathrm{REF}}: \\
\text { No sales of these } \\
\text { vehicles are } \\
\text { attributed to } \mathrm{ZEV} \\
\text { policy, so this case } \\
\text { is identical to the } \\
\text { reference case for } \\
\text { these vehicles }\end{array}$ & 1,440 & 1,580 & 2,530 & 1,540 & $\begin{array}{l}0 \text { to } \\
9,560\end{array}$ & 98 & $\begin{array}{l}206,252 \\
\text { to } \\
215,812\end{array}$ & 223,000 \\
\hline AFVI & $\begin{array}{l}\text { REF + } \\
\text { AFVI }\end{array}$ & $n_{\mathrm{AFVI}}$ & $\begin{array}{l}n_{\mathrm{AFVI}}=n_{\mathrm{CARB}}- \\
n_{\mathrm{ATRBZEV}}: \\
\text { CARB projections } \\
\text { minus AFV sales } \\
\text { attributed to ZEV by } \\
\text { CARB }\end{array}$ & $\begin{array}{l}n_{\mathrm{AFVI}}=n_{\mathrm{CARB}}: \\
\text { No sales of these } \\
\text { vehicles are } \\
\text { attributed to } \mathrm{ZEV} \\
\text { policy }\end{array}$ & 337 & 479 & 755 & 40 & 9,560 & 98 & 211,731 & 223,000 \\
\hline $\begin{array}{l}\text { REF } \\
\text { (range of } \\
\text { assumpti } \\
\text { ons } \\
\text { shown } \\
\text { for AFV } \\
\text { sales } \\
\text { induced } \\
\text { by AFV } \\
\text { incentive } \\
\text { s) }\end{array}$ & $\begin{array}{l}\text { Pure } \\
\text { fleet } \\
\text { GHG } \\
\text { standard } \\
\text { s alone }\end{array}$ & $n_{\mathrm{REF}}$ & $\begin{array}{l}0 \leq n_{\mathrm{REF}} \leq n_{\mathrm{AFVI}}: \\
\text { AFV sales unknown in } \\
\text { the absence of } \mathrm{ZEV} \\
\text { mandate and AFV } \\
\text { incentives. Adopt } \\
n_{\mathrm{REF}}=\frac{n_{\mathrm{AFVI}}}{2} \text { as a base } \\
\text { case and examine full } \\
\text { range from } n_{\mathrm{REF}}=0 \\
\text { to } n_{\mathrm{REF}}=n_{\mathrm{AFVI}} \text { in } \\
\text { sensitivity analysis. }\end{array}$ & $\begin{array}{l}0 \leq n_{\mathrm{REF}} \leq n_{\mathrm{AFVI}}: \\
\text { AFV sales unknown } \\
\text { in the absence of } \\
\mathrm{ZEV} \text { mandate and } \\
\text { AFV incentives. } \\
\text { Adopt } n_{\mathrm{REF}}=\frac{n_{\mathrm{AFVI}}}{2} \\
\text { as a base case and } \\
\text { examine full range } \\
\text { from } n_{\mathrm{REF}}=0 \text { to } \\
n_{\mathrm{REF}}=n_{\mathrm{AFVI}} \text { in } \\
\text { sensitivity analysis. }\end{array}$ & $\begin{array}{l}0 \text { to } \\
337\end{array}$ & 0 to 479 & 0 to 755 & $\begin{array}{l}0 \text { to } \\
40\end{array}$ & $\begin{array}{l}0 \text { to } \\
9,560\end{array}$ & 0 to 98 & $\begin{array}{l}211,731 \\
\text { to } \\
223,000\end{array}$ & 223,000 \\
\hline
\end{tabular}


Table S12: CARB/AEO with historic ZEV AFV sales volume assumptions and rationale for four policy scenarios

\begin{tabular}{|c|c|c|c|c|c|c|c|c|c|c|c|c|}
\hline \multirow[t]{2}{*}{ Scenario } & \multirow[t]{2}{*}{ Policies } & \multirow{2}{*}{ Sales } & \multirow{2}{*}{$\begin{array}{l}\text { Sales of BEVs, } \\
\text { PHEVs, and FCEVs }\end{array}$} & \multirow{2}{*}{$\begin{array}{l}\text { Sales of FFVs and } \\
\text { CNGVs }\end{array}$} & \multicolumn{8}{|c|}{ (thousands of sales) } \\
\hline & & & & & BEV & PHEV 10 & $\mathrm{PHEV}_{40}$ & FCV & FFV & CNGV & $\mathrm{CV}$ & Total \\
\hline BOTH & $\begin{array}{l}\mathrm{REF}+ \\
\mathrm{ZEV}+ \\
\mathrm{AFVI}\end{array}$ & $n_{\mathrm{BOTH}}$ & $\begin{array}{l}n_{\mathrm{BOTH}}=n_{\mathrm{CARB}}: \\
\text { CARB projections } \\
\text { reflect the projected } \\
\text { policy context (both } \\
\text { policies) }\end{array}$ & $\begin{array}{l}n_{\mathrm{BOTH}}=n_{\mathrm{CARB}}: \\
\text { CARB projections } \\
\text { reflect the projected } \\
\text { policy context (both } \\
\text { policies) }\end{array}$ & 1,440 & 1,580 & 2,530 & 1,540 & 9,560 & 98 & 206,252 & 223,000 \\
\hline ZEV & $\begin{array}{l}\mathrm{REF}+ \\
\mathrm{ZEV}\end{array}$ & $n_{\mathrm{ZEV}}$ & $\begin{array}{l}n_{\mathrm{ZEV}}=n_{\mathrm{CARB}}: \\
\text { We assume the } \mathrm{ZEV} \\
\text { mandate is a stronger } \\
\text { driver than the AFV } \\
\text { incentives and AFV } \\
\text { incentives do not } \\
\text { increase sales beyond } \\
\text { the ZEV mandate, so } \\
\text { removing AFV } \\
\text { incentives without } \\
\text { removing the ZEV } \\
\text { mandate does not } \\
\text { reduce AFV sales }\end{array}$ & $\begin{array}{l}n_{\mathrm{ZEV}}=n_{\mathrm{REF}}: \\
\text { No sales of these } \\
\text { vehicles are } \\
\text { attributed to } \mathrm{ZEV} \\
\text { policy, so this case } \\
\text { is identical to the } \\
\text { reference case for } \\
\text { these vehicles }\end{array}$ & 1,440 & 1,580 & 2,530 & 1,540 & $\begin{array}{l}0 \text { to } \\
9,560\end{array}$ & 98 & $\begin{array}{l}206,252 \\
\text { to } \\
215,812\end{array}$ & 223,000 \\
\hline AFVI & $\begin{array}{l}\text { REF + } \\
\text { AFVI }\end{array}$ & $n_{\mathrm{AFVI}}$ & $\begin{array}{l}n_{\mathrm{AFVI}}=n_{\mathrm{CARB}}- \\
n_{\mathrm{ATRBZEV}}: \\
\text { CARB projections } \\
\text { minus AFV sales } \\
\text { attributed to ZEV by } \\
\text { CARB }\end{array}$ & $\begin{array}{l}n_{\mathrm{AFVI}}=n_{\mathrm{CARB}}: \\
\text { No sales of these } \\
\text { vehicles are } \\
\text { attributed to } \mathrm{ZEV} \\
\text { policy }\end{array}$ & 1,060 & 744 & 1,190 & 1,540 & 9,560 & 98 & 208,808 & 223,000 \\
\hline $\begin{array}{l}\text { REF } \\
\text { (range of } \\
\text { assumpti } \\
\text { ons } \\
\text { shown } \\
\text { for AFV } \\
\text { sales } \\
\text { induced } \\
\text { by AFV } \\
\text { incentive } \\
\text { s) }\end{array}$ & $\begin{array}{l}\text { Pure } \\
\text { fleet } \\
\text { GHG } \\
\text { standard } \\
\text { s alone }\end{array}$ & $n_{\mathrm{REF}}$ & $\begin{array}{l}0 \leq n_{\mathrm{REF}} \leq n_{\mathrm{AFVI}}: \\
\mathrm{AFV} \text { sales unknown in } \\
\text { the absence of } \mathrm{ZEV} \\
\text { mandate and AFV } \\
\text { incentives. Adopt } \\
n_{\mathrm{REF}}=\frac{n_{\mathrm{AFVI}}}{2} \text { as a base } \\
\text { case and examine full } \\
\text { range from } n_{\mathrm{REF}}=0 \\
\text { to } n_{\mathrm{REF}}=n_{\mathrm{AFVI}} \text { in } \\
\text { sensitivity analysis. }\end{array}$ & $\begin{array}{l}0 \leq n_{\mathrm{REF}} \leq n_{\mathrm{AFVI}}: \\
\text { AFV sales unknown } \\
\text { in the absence of } \\
\mathrm{ZEV} \text { mandate and } \\
\text { AFV incentives. } \\
\text { Adopt } n_{\mathrm{REF}}=\frac{n_{\mathrm{AFVI}}}{2} \\
\text { as a base case and } \\
\text { examine full range } \\
\text { from } n_{\mathrm{REF}}=0 \text { to } \\
n_{\mathrm{REF}}=n_{\mathrm{AFVI}} \text { in } \\
\text { sensitivity analysis. }\end{array}$ & $\begin{array}{l}0 \text { to } \\
1,060\end{array}$ & 0 to 744 & $\begin{array}{l}0 \text { to } \\
1,190\end{array}$ & $\begin{array}{l}0 \text { to } \\
1,540\end{array}$ & $\begin{array}{l}0 \text { to } \\
9,560\end{array}$ & 0 to 98 & $\begin{array}{l}208,808 \\
\text { to } \\
223,000\end{array}$ & 223,000 \\
\hline
\end{tabular}



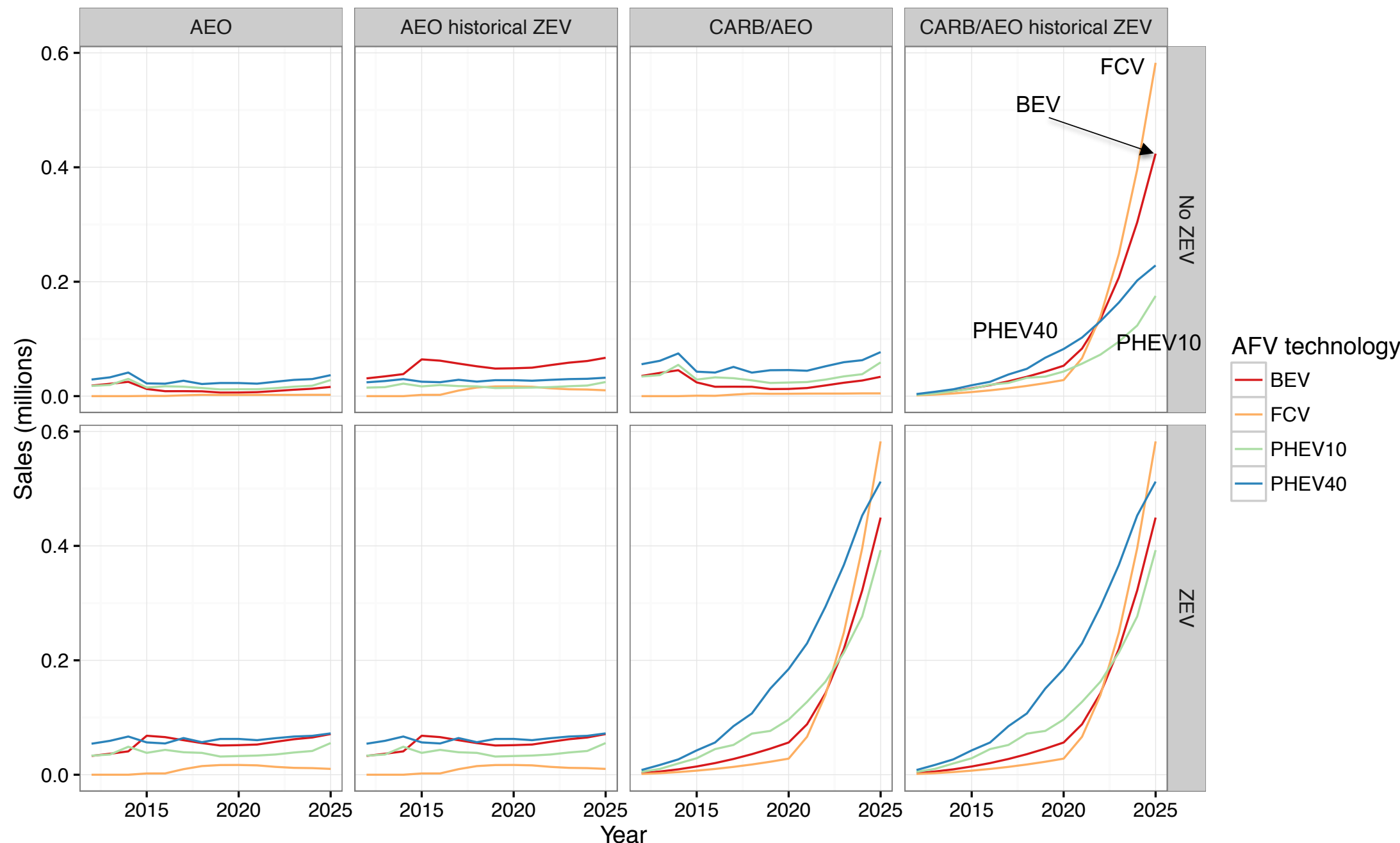

- PHEV10

- PHEV40

Figure S6: Four scenarios of sales projections of alternative fuel vehicles including battery electric vehicles, fuel cell vehicles, and plug-in hybrid vehicles from 2012 through 2025. Each scenario additionally forecasts sales based on the absence/presence of the ZEV mandate. In the "AEO" and "CARB/AEO" scenarios,

the ZEV mandate's effect on sales is captured by the AEO's attribution of AFV sales to ZEV. In the "historical ZEV" scenarios, the ZEV mandate's effect on
sales is captured by a comparison of historical AFV sales in states with a ZEV requirement versus states without a ZEV requirement. 
6 ALTERNATIVE ADOPTION SCENARIO RESULTS
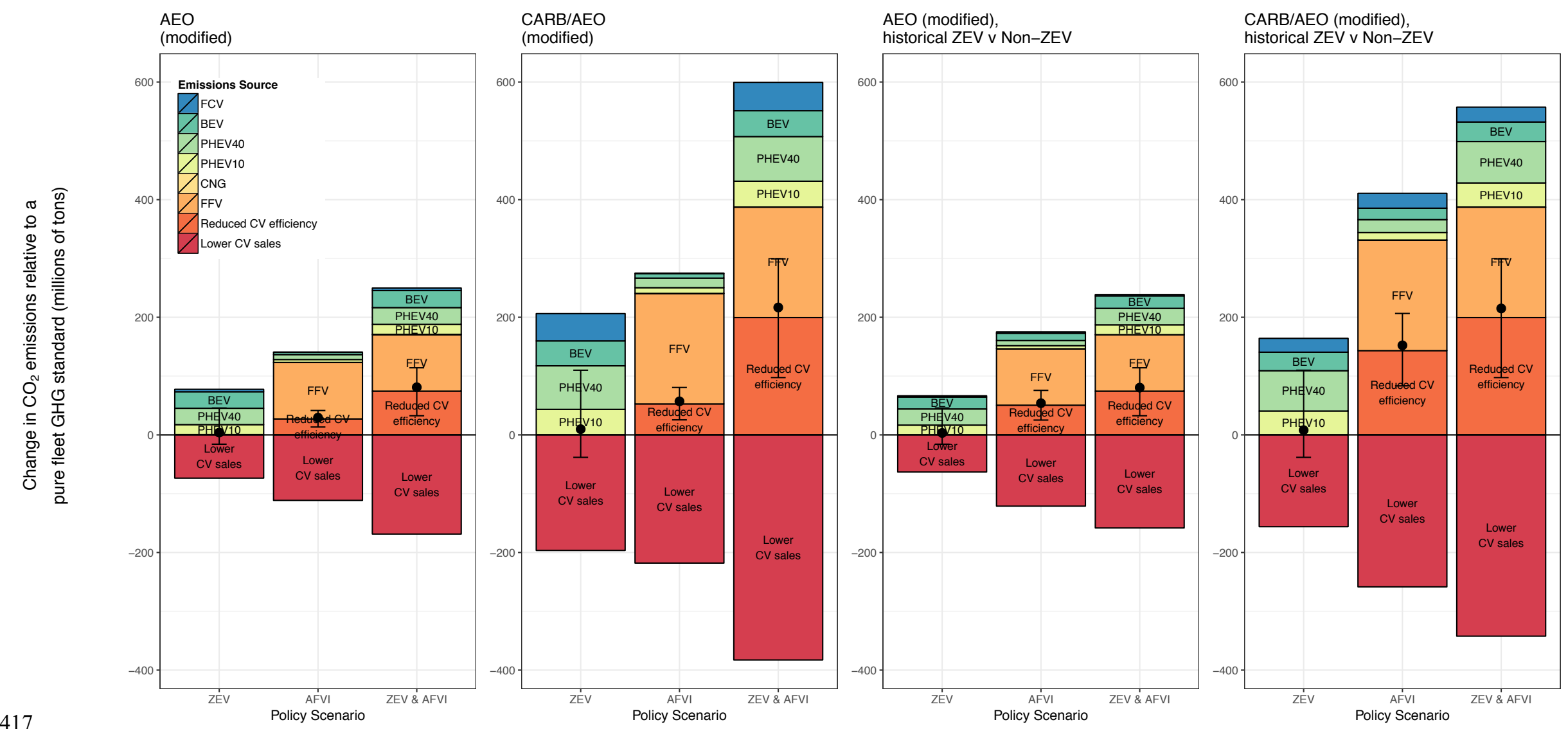

Figure S7: Four scenarios of cumulative change in emissions for vehicles sold from 2012 through 2025 relative to a baseline scenario of pure light-duty fleet GHG standards. Each scenario represents different assumption of AFV sales (see Figure S6). Dots indicate the net change in emissions and the error bars capture the interval of uncertainty for electricity grid emissions, baseline fleet sales projections, two-cycle to five-cycle test conversion, and life-cycle emissions from the battery production. 

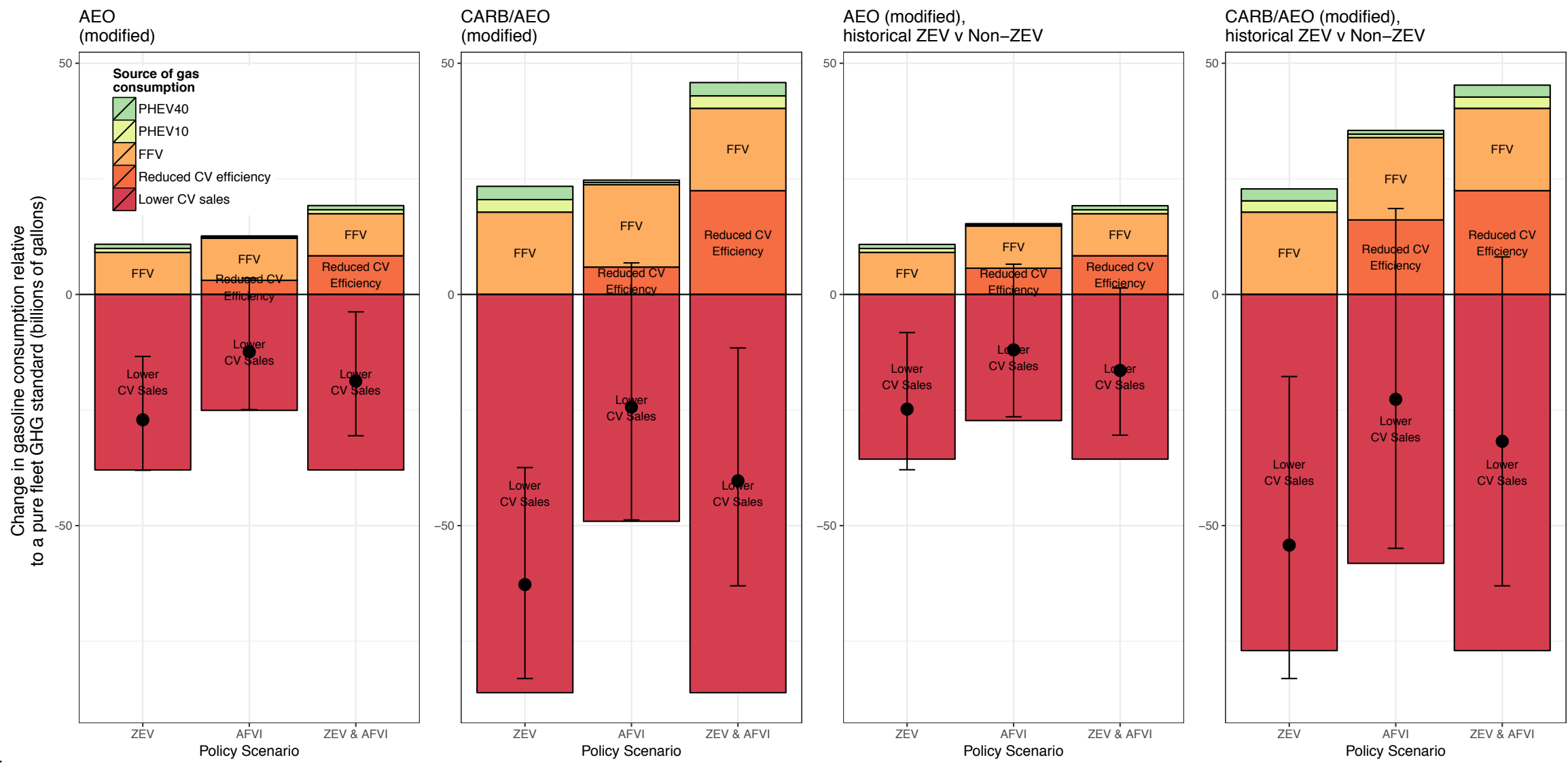

Figure S8: Four scenarios of cumulative change in gasoline consumption for vehicles sold from 2012 through 2025 relative to a baseline scenario with pure lightduty GHG standards. Each scenario represents different assumption of AFV sales (see Figure S6). Dots indicate the net change in emissions and the error bars capture the interval of uncertainty for electricity grid emissions, baseline fleet sales projections, and two-cycle to five-cycle test conversion. 


\section{BIBLIOGRAPHY}

Anderson, Soren T, and James M Sallee. 2011. "Using loopholes to reveal the marginal cost of regulation: The case of fuel-economy standards." The American Economic Review 101 (4): 1375-1409.

Austin, David, and Terry Dinan. 2005. "Clearing the air: The costs and consequences of higher CAFE standards and increased gasoline taxes." Journal of Environmental Economics and Management 50 (3): 562-582.

Bezdek, Roger H., and Robert M. Wendling. 2005. "Potential long-term impacts of changes in US vehicle fuel efficiency standards." Energy Policy 33 (3): 407-419.

DeVynne, Farquharson, Paulina Jaramillo, Greg Schivley, Kelly Klima, Derrick Carlson, and Constantine Samaras. 2016. "Beyond Global Warming Potential. A Comparative Application of Climate Impact Metrics for the Life Cycle Assessment of Coal and Natural Gas Based Electricity." Journal of Industrial Ecology 21 (4).

Dunn, JB, L Gaines, M Barnes, M Wang, and J Sullivan. 2012. "Material and energy flows in the materials production, assembly, and end-of-life stages of the automotive lithium-ion battery life cycle." Argonne National Labs.

Gerard, David, and Lester Lave. 2003. "The economics of CAFE reconsidered: a response to CAFE critics and a case for fuel economy standards." AEI-Brookings Joint Center for Regulatory Studies, Regulatory Analysis 03-01.

Granovskii, Mikhail, Ibrahim Dincer, and Marc A Rosen. 2006. "Economic and environmental comparison of conventional, hybrid, electric and hydrogen fuel cell vehicles." Journal of Power Sources 159 (2): 11861193.

Greene, David L. 1998. "Why CAFE Worked." Energy Policy (Elsevier) 26 (8): 595-613.

Hart, Kathy, Mary Ann Curran, Clive Davies, David E. Meyer, Linda Gaines, Jennifer Dunn, John Sullivan, et al. 2013. "Lithium-Ion Batteries and Nanotechnology for Electric Vehicles: A Life Cycle Assessment." US Environmental Protection Agency, 1-120.

Kleit, Andrew N. 2004. "Impacts of Long-Range Increases in the Fuel Economy (CAFE) Standard." Economic Inquiry (Wiley Online Library) 42 (2): 279-294.

Klier, Thomas, and Joshua Linn. 2012. "New-vehicle characteristics and the cost of the Corporate Average Fuel Economy standard." The RAND Journal of Economics (Wiley Online Library) 43 (1): 186-213.

Klier, Thomas, and Joshua Linn. 2015. "The Effect of Vehicle Fuel Economy Standards on Technology Adoption." Resources for the Future.

Leard, Benjamin, and Virginia McConnell. 2015. "New Markets for Pollution and Energy Efficiency: Credit Trading under Automobile Greenhouse Gas and Fuel Economy Standards." Resources for the Future.

Liu, Yimin, and Gloria Helfand. 2009. "The Alternative Motor Fuels Act, alternative-fuel vehicles, and greenhouse gas emissions." Transportation Research Part A 43: 755-764.

Majeau-Bettez, Guillaume, Troy R Hawkins, and Anders Hammer Stromman. 2011. "Life cycle environmental assessment of lithium-ion and nickel metal hydride batteries for plug-in hybrid and battery electric vehicles." Environmental Science \& Technology 45 (10): 4548-4554.

McManus, Walter. 2007. The Impact of Attribute-Based Corporate Average Fuel Economy (CAFE) Standards: Preliminary Findings. Technical Report, University of Michigan Transportation Research Institute, Ann Arbor: UMTRI.

Notter, Dominic A, Marcel Gauch, Rolf Widmer, Patrick Wager, Anna Stamp, Rainer Zah, and Hans-Jorg Althaus. 2010. "Contribution of Li-ion batteries to the environmental impact of electric vehicles." Environmental Science \& Technology (ACS Publications) 44 (17): 6550-6556.

Reynaert, Mathias. 2014. "Abatement Strategies and the Cost of Environmental Regulation: Emission Standards on the European Car Market." KU Leuven Center for Economic Studies.

Shiau, Ching-Shin Norman, Jeremy J Michalek, and Chris T Hendrickson. 2009. "A structural analysis of vehicle design responses to Corporate Average Fuel Economy policy." Transportation Research Part A: Policy and Practice (Elsevier) 43 (9): 814-828.

US Department of Transportation. 2002. "Effects of the Alternative Motor Fuels Act CAFE Incentives Policy." Report to Congress, Washington DC.

Whistance, Jarrett, and Wyatt Thompson. 2014. "The role of CAFE standards and alternative-fuel vehicle production credits in US biofuels markets." Energy Policy 74: 147-157.

Whitefoot, Kate S, and Steven J Skerlos. 2012. "Design incentives to increase vehicle size created from the US footprint-based fuel economy standards." Energy Policy (Elsevier) 41: 402-411. 
482

483

484

485

486

487

Zackrisson, Mats, Lars Avellan, and Jessica Orlenius. 2010. "Life cycle assessment of lithium-ion batteries for plugin hybrid electric vehicles--Critical issues." Journal of Cleaner Production (Elsevier) 18 (15): 1519-1529.

Zivin, Graff, Matthew J. Kotchen, and Erin T. Mansur. 2014. "Spatial and temporal heterogeneity of marginal emissions: Implications for electric cars and other electricity-shifting policies." Journal of Economic Behavior \& Organization 107: 248-268. 